\title{
Distribution and abundance of western gray whales during a seismic survey near Sakhalin Island, Russia
}

\author{
S. B. Yazvenko • T. L. McDonald • S. A. Blokhin • \\ S. R. Johnson • S. K. Meier • H. R. Melton • \\ M. W. Newcomer $\cdot$ R. M. Nielson • \\ V. L. Vladimirov $\cdot$ P. W. Wainwright
}

Received: 21 April 2006 /Accepted: 20 April 2007 / Published online: 26 September 2007

(C) Springer Science + Business Media B.V. 2007

\begin{abstract}
Exxon Neftegas Limited, operator of the Sakhalin-1 consortium, is developing oil and gas reserves on the continental shelf off northeast Sakhalin Island, Russia. DalMorNefteGeofizika (DMNG), on behalf of the Sakhalin-1 consortium, conducted a
\end{abstract}

M. W. Newcomer, Deceased.

S. B. Yazvenko $(\bowtie) \cdot$ S. R. Johnson $\cdot$ S. K. Meier •

P. W. Wainwright

LGL Limited, Environmental Research Associates,

9768 Second Street,

Sidney BC, V8L 3Y8, Canada

e-mail: yazvenko@1gl.com

T. L. McDonald • R. M. Nielson

Western EcoSystems Technology, Inc.,

2003 Central Avenue,

Cheyenne, WY 82001, USA

S. A. Blokhin • V. L. Vladimirov Pacific Research Center for Fisheries and Oceanography (TINRO-Center),

4 Shevchenko Alley,

Vladivostok, 690950, Russia

H. R. Melton

ExxonMobil Upstream Research, PO Box 2189, 3319 Mercer Street, Houston, TX 77252-2189, USA

M. W. Newcomer

22371 Hartman Dr.,

Los Altos, CA 94024, USA
3-D seismic survey of the Odoptu license area during 17 August-9 September 2001. A portion of the primary known feeding area of the endangered western gray whale (Eschrichtius robustus) is located adjacent to the seismic block. The data presented here were collected as part of daily monitoring to determine if there was any measurable effect of the seismic survey on the distribution and abundance of western gray whales. Mitigation and monitoring program included aerial surveys conducted between 19 July and 19 November using the methodology outlined by the Southern California High Energy Seismic Survey team (HESS). These surveys provided documentation of the distribution, abundance and bottom feeding activity of western gray whales in relation to seismic survey sounds. From an operations perspective, the aerial surveys provided near real-time data on the location of whales in and outside the feeding area, and documented whether whales were displaced out of an area normally used as feeding habitat. The objectives of this study were to assess (a) temporal changes in the distribution and abundance of gray whales in relation to seismic survey, and (b) the influence of seismic survey, environmental factors, and other variables on the distribution and abundance of gray whales within their preferred feeding area adjacent to Piltun Bay. Multiple regression analysis revealed a limited redistribution of gray whales southward within the Piltun 
feeding area when the seismic survey was fully operational. A total of five environmental and other variables unrelated to seismic survey (date and proxies of depth, sea state and visibility) and one seismic survey-related variable ( $\operatorname{seg} 3 d$, i.e., received sound energy accumulated over 3 days) had statistically significant effects on the distribution and abundance of gray whales. The distribution of two to four gray whales observed on the surface (i.e., about five to ten whales in total) has likely been affected by the seismic survey. However, the total number of gray whales observed within the Piltun feeding area remained stable during the seismic survey.

Keywords Multiple regression · Sakhalin · Odoptu · Seismic survey · Air gun · Environmental impact . Mitigation - Distribution · Abundance - Western gray whales $\cdot$ Environment $\cdot$ Oil $\cdot$ Continental shelf

\section{Introduction}

The Western North Pacific population of gray whale (Eschrichtius robustus), hereinafter western gray whale, feeds during the ice-free season off northeastern Sakhalin Island, Russia, and is one of the most endangered populations of cetaceans. This population is listed as Category 1 ("threatened with extinction") in the Red Book of Russian Federation (Anonymous 2001). The International Union for the Conservation of Nature (IUCN) listed western gray whales as a critically endangered population based on its geographic and genetic separation from the eastern population (LeDuc et al. 2002) and likelihood that fewer than 50 reproductively active individuals remain (Hilton-Taylor 2000).

Exxon Neftegas Limited, operator of the Sakhalin1 consortium, is developing oil and gas reserves on the nearshore continental shelf off northeastern Sakhalin Island, Russia. DalMorNefteGeofizika (DMNG), on behalf of the Sakhalin-1 consortium, conducted a 3-D seismic survey of the Odoptu license area from 17 August to 9 September 2001. A 1,640 in. $^{3}$ (26.9 1) airgun array, $17 \times 13 \mathrm{~m}$ in size, consisting of three lines by seven airguns, was used. The array's sound output was decreased by $\sim 50 \%$ by turning off specific airguns in the original 3,090 in. ${ }^{3}$ array (Borisov et al. 2002; Rutenko et al. 2007). A mitigation and monitoring program (Johnson 2002;
Johnson et al. 2007) was designed to minimise impact on feeding gray whales during the seismic survey, including potential displacement away from known feeding grounds. One component of the mitigation and monitoring program included replicated and systematic aerial surveys that were carried out to determine the distribution, abundance and bottom feeding activity of western gray whales in relation to seismic survey sound. This paper presents the findings on the distribution and abundance of gray whales adjacent to Piltun Bay before, during and after the seismic survey in 2001. The main objectives of this study were (a) to determine if gray whales were displaced outside of the known feeding habitat; (b) to assess temporal changes in the distribution and abundance of gray whales within their feeding habitat during seismic survey, and (c) to assess the influence of seismic survey, environmental and other variables on the distribution of gray whales within their feeding habitat. An assessment of the effects of the seismic survey on feeding activity of gray whales is presented elsewhere (Yazvenko et al. 2007).

\section{Materials and methods}

\section{Aerial survey area}

The aerial survey grid covered nearshore areas near Piltun Bay and adjacent to the Odoptu seismic block, i.e., all areas where western gray whales were known to feed along the Sakhalin coast from 1983 to 2001 (Fig. 21; Blokhin et al. 1985, 2002, 2003, 2004; Berzin et al. 1988, 1990, 1991; Vladimirov 1994; Blokhin 1996; Sobolevsky 2000, 2001; Würsig et al. 2000; Weller et al. 2000, 2001; Yazvenko et al. 2002; Vladimirov et al. 2005; Meier et al. 2002, 2007). Four transect lines (hereinafter "lines") parallel to shore spaced $2 \mathrm{~km}$ apart were established (two lines in waters $<20 \mathrm{~m}$ deep and two lines outside the $20-\mathrm{m}$ isobath), covering $\sim 90 \mathrm{~km}$ of coastline from $52^{\circ} 43^{\prime} \mathrm{N}$ to $53^{\circ} 31^{\prime} \mathrm{N}$ and extending seaward beyond the known feeding habitat of gray whales adjacent to Piltun Bay (hereinafter called "Piltun feeding area"). Each line was subdivided into five "blocks" numbered sequentially from south to north and nearly equal in size ( $\sim 0 \mathrm{~km}^{2}$ each; Fig. 1). A broad-scale aerial survey grid $(\sim 300 \times 20 \mathrm{~km}$; Fig. 22$)$ was also established to document regional distribution of gray whales and 
Fig. 1 Piltun aerial survey grid developed for the 3-D seismic survey monitoring. Four $90 \mathrm{~km}$ long transect lines were numbered seawards. Each of the four lines were subdivided into five "blocks"

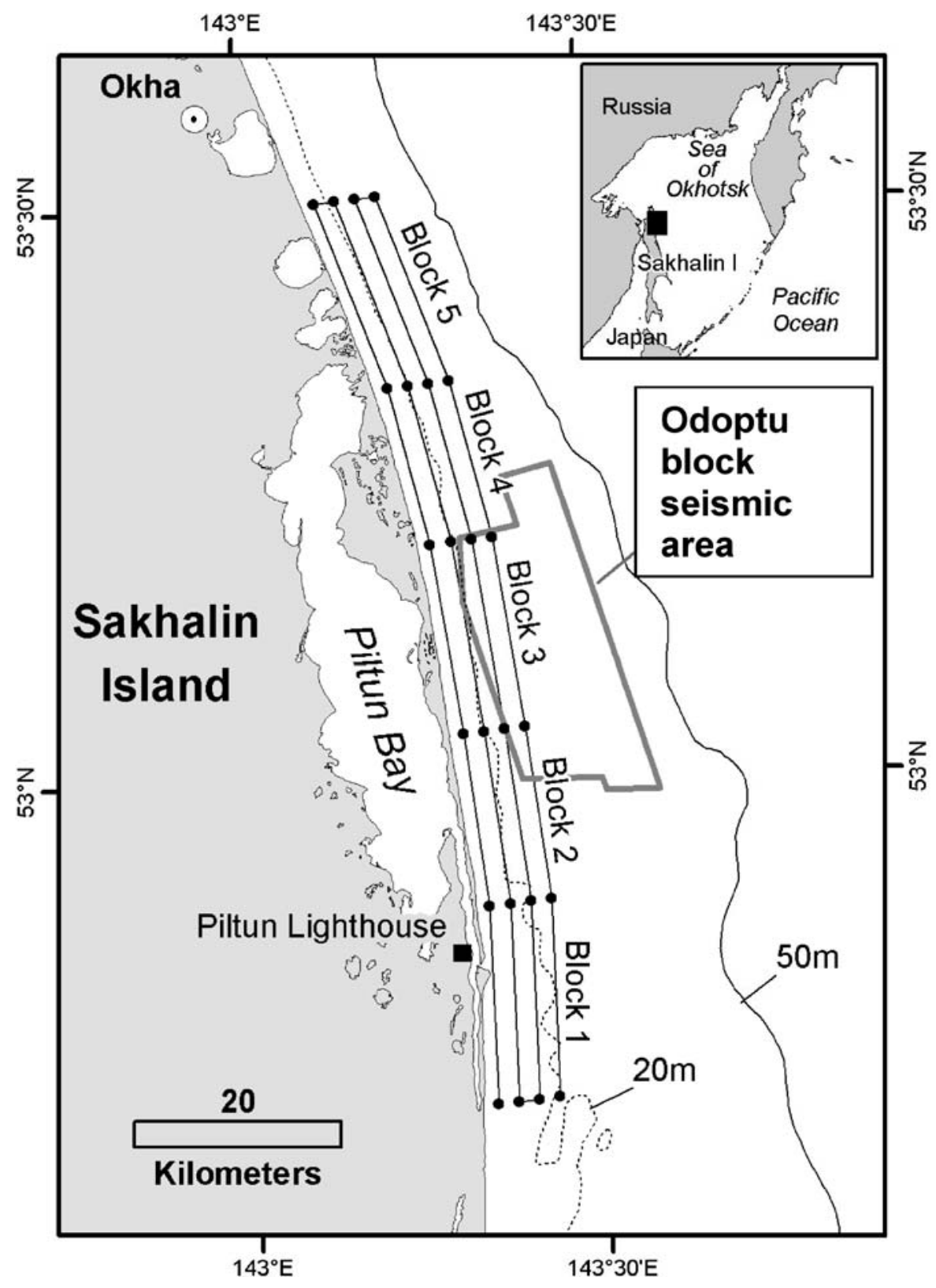

their possible displacement outside their feeding grounds.

\section{Survey design}

After several attempts failed due to bad weather, the first successful aerial survey was flown on 19 July 2001. Weather permitting, the aerial surveys were conducted daily or several times per day from 19 July to 19 November, including the period of the seismic survey (17 August to 9 September) and after its cessation (9 September-19 November). The seismic survey ceased at 3:45 A.M. on 9 September 2001, local time. All but one aerial surveys were flown at $300 \mathrm{~m}$ above sea level (ASL); one survey (7 October) was flown at various altitudes due to rapid changes in weather conditions. Survey procedures generally followed those recommended by the High Energy Seismic Survey team (HESS) guidelines for southern California waters (High Energy Seismic Survey Team (HESS) 1999). Aerial surveys were part of the mitigation and monitoring program (Johnson 2002; 
Table 1 Periods within the Odoptu seismic regime, Northeast Sakhalin Shelf, Okhotsk Sea, Russia, 2001

\begin{tabular}{|c|c|c|}
\hline Dates & $\begin{array}{l}\text { Seismic } \\
\text { periods }\end{array}$ & Seismic survey \\
\hline 19 July to 2 August (morning) & Pre-Seismic & Pre-seismic: no seismic survey \\
\hline 2 August (afternoon) to 5 August & Calibration & $\begin{array}{l}\text { Seismic calibration. Sound propagation from air gun array tested at various } \\
\text { distances from shore. }\end{array}$ \\
\hline 6-11 August & Calibration & No seismic activities due to poor weather \\
\hline 12-14 August & Calibration & $\begin{array}{l}\text { Seismic calibration. Sound propagation from air gun array tested at various } \\
\text { distances from shore. }\end{array}$ \\
\hline 15-16 August & Calibration & No seismic activities due to poor weather \\
\hline 17-21 August (morning) & Seismic & Seismic survey in the offshore part of the seismic block only \\
\hline $\begin{array}{l}21 \text { August (afternoon)-early morning } 9 \\
\text { September }\end{array}$ & Seismic & Seismic survey in the offshore and nearshore parts of the seismic block \\
\hline $\begin{array}{l}\text { Early morning } 9 \text { September-19 } \\
\text { November }\end{array}$ & $\begin{array}{l}\text { Post- } \\
\text { Seismic }\end{array}$ & Post-seismic: no seismic survey \\
\hline
\end{tabular}

Johnson et al. 2007) and were used in daily planning. Other components of the program included a vesselbased monitoring program (Meier et al. 2002), acoustic monitoring of noise levels on the periphery of the area frequented by gray whales (Borisov et al. 2002; Rutenko et al. 2007), and a gray whale behaviour monitoring program (Würsig et al. 2002; Gailey et al. 2007).

Prior to 4 August, aerial surveys were conducted in a twin-engine MI-8 helicopter and flown with three marine mammal observers, one on each side of the helicopter behind the pilots and one in the front nosepod of the cockpit (i.e., forward of and between the pilot and co-pilot). Beginning on 4 August, an Antonov 28 (AN-28) twin engine turboprop fixedwing aircraft was used, and two side observers and a data recorder conducted the surveys. Both aircraft were equipped with a radar altimeter. In addition to the aircraft GPS, marine mammal observers had a dedicated Garmin $($ III+ GPS that every $30 \mathrm{~s}$ automatically logged track-line positions of the survey route (see Yazvenko et al. 2002 and Blokhin et al. 2002 for details).

\section{Survey procedures}

Western gray whale sighting data were recorded from 19 July and continued through 19 November, 71 days after seismic survey ceased. A whale sighting was defined as an observation of a group, i.e., of one or more western gray whales. Whales were considered a group if the distance between them was $<5$ whale body lengths. GPS coordinates were recorded as waypoints at the point of closest approach to a gray whale sighted during the survey, i.e., when the whale was directly perpendicular to the aircraft. Clinometers were used to measure the vertical angle to gray whale sightings. These angles were used to determine the distance of the sighting from the aircraft. Location information for seismic support vessels and small craft were recorded in the same manner as for whales.

The probability of detecting a whale in the zone beneath the aircraft was found to be lower than for the part of the line beyond this strip. The width of the low detection zone was dependent on aircraft height ASL. When the aircraft flew at $300 \mathrm{~m}(\sim 1,000 \mathrm{ft}) \mathrm{ASL}$, the low detection zone was $\sim 400 \mathrm{~m}$ wide $(200 \mathrm{~m}$ on either side of the aircraft). During an average $4.1 \mathrm{~min}$ surface-respiration-dive cycle recorded in 2001 in the Piltun feeding area ("surface time" plus "dive time" in Würsig et al. 2002), gray whales spent $1.6 \pm 1.84 \mathrm{~min}$ on the surface ("surface time") and $2.5 \pm 0.92 \mathrm{~min}$ underwater ("dive time"). Thus, gray whales were visible for detection about $40 \%$ of the time though the variability of surface time was high. At ground speeds of $\sim 180 \mathrm{~km} / \mathrm{h}$ for the MI- 8 and $\sim 200 \mathrm{~km} / \mathrm{h}$ for the AN28 , a large fraction of gray whales were probably not detected. The analyses below deal with the numbers of gray whales observed at the surface; an average correction for availability (Buckland et al. 1993) was computed as a final step in the analysis. Distances to sightings were not adjusted to account for earth curvature (Lerczak and Hobbs 1998); therefore, they are slightly underestimated. 
Initial data processing

Four study periods were established for the analysis (Table 1):

1. The pre-seismic period (19 July-morning of 2 August),

2. The calibration survey during testing of the seismic equipment (afternoon of 2 August-16 August),

3. The seismic survey period (17 August-9 September)

4. The post-seismic period (9 September-19 November).

The geographic area defined by each of the five blocks along each of the four lines was the basic experimental unit within which whale responses, environmental variables, and industrial sound variables were measured. A survey was defined as one flight over one of the blocks. A small proportion $(4.5 \%)$ of gray whales were sighted along lines 3 and 4 (the two lines farthest from shore) and in block 5 . To provide stability and precision of statistical analyses, these data were excluded from the analyses. These exclusions left four blocks (geographic areas) along each of two nearshore lines, i.e., eight blocks in total, in the analysis. Whale sightings that occurred while the aircraft was turning or travelling to another lines were not considered.

Estimating gray whale densities

Standard line transect methods (Buckland et al. 1993; Laake et al. 1993) were used to estimate sightability at different distances from the line. Surveys flown during poor sightability conditions were not eliminated from the data set that was used to estimate sightability functions. Separate sightability functions were developed for the MI- 8 helicopter vs. the AN-28 fixed-wing aircraft, and for good and poor sightability conditions; overall, four functions were developed. Poor sightability conditions were defined as visibility $\leq 600 \mathrm{~m}$, white cap index $\geq 1.5$ (i.e., abundant white caps that mask the whales), fog $\geq 1$ (light fog/haze or dense fog), or sea state index $\geq 2.5$ (the sea state index was correlated with but not identical to the Beaufort scale). The two weather and sea state variables considered as possible stratification variables were overcast, representing the percentage of overcast sky $(0,20,40,60,80$ and $100 \%)$ and white_caps, representing an index of the abundance of white caps $(0,0.5,1.0,1.5,2.0)$. For each variable, Wilcoxon rank-sum and Kruskal-Wallis tests (Sokal and Rohlf 1981) were used to test for differences in the distribution of sightings at different distances perpendicular to the transect between levels of the variable. Rejection of the null hypothesis of equal distributions was regarded as evidence that the variable should be used to define strata. Once defined, separate sightability functions were estimated in each stratum using program DISTANCE 4.1 (http://www.ruwpa.st-and. ac.uk/distance). The sightability function, $g(x)$, represented the probability of sighting a whale group at perpendicular distance $x$ given the whale group was present. Under the assumptions of line transect sampling, $g(x)$ was related to another function, $f(x)$, the probability that a whale group was located at perpendicular distance $x$ given that it was sighted. The relationship between functions $g(x)$ and $f(x)$ is shown in Eq. 1;

$f(x)=\frac{g(x)}{\int_{0}^{w} g(x) d x}$

where $w$ was half-width of the transect. If sightability did not decline with increasing distance from the transect, $g(x)=1$ and $f(x)=1 / w$. Estimates of the density of whales at the surface for a certain length of transect were obtained from Eq. 2;

$\widehat{D}=\frac{n \times \widehat{f}(0) \times \widehat{E}(s)}{2 L}$

where $\widehat{D}$ was the sightability-corrected density of whales at the surface $\left(\# / \mathrm{km}^{2}\right), n$ was the number of whale groups observed from the aircraft, $\widehat{f}(0)$ was the estimated proportion of sighted whale groups on (or very near) the line, $\widehat{E}(s)$ was the average number of individuals in each group, and $L$ was the length of the transect lines in kilometers (Buckland et al. 1993). Program DISTANCE 4.1 estimated $g(x)$ from observed distances and, in turn, computed $\widehat{f}(0)$ as the inverse of the area under $g(x)$, i.e., $\widehat{f}(0)=\left(\int_{0}^{w} \widehat{g}(x) d x\right)^{-1}$. Average group size, $\widehat{E}(s)$, was calculated from the observed groups and varied across blocks, periods, and aircraft. When group size is measured from a passing aircraft, $\widehat{E}(s)$ is known to be underestimated because whales below the surface may not be counted. 
Table 2 List of environmental and other nonseismic related variables considered for inclusion in the quasi-likelihood regression model
*Variables removed from analysis due to a large number of missing observations or insufficient data

**Variables removed from analysis due to high colinearity with another variable

$* * *$ Due to missing values, aspect was considered in the secondary analysis, not the primary.

\begin{tabular}{|c|c|}
\hline Variable & Description \\
\hline line & Line number $(1$ or 2$)$ \\
\hline block & Block number (1 to 4$)$ \\
\hline visibility & Visibility index $(0,0.5,1,1.5,2,2.5,3,3.5,4,4.5,5)$ \\
\hline white_caps & Incidence of white-caps $(0,0.5,1,1.5,2)$ \\
\hline fog & Index of fog $(0,1,2)$ \\
\hline wind_direction & Direction of wind (N, E, S, W) \\
\hline wind_speed & Wind speed $(\mathrm{m} / \mathrm{s})$ \\
\hline air_temp & Air temperature $(\mathrm{C})$ \\
\hline wave_height & Wind wave height (m) \\
\hline swell_height & Swell height $(\mathrm{m})$ \\
\hline swell_period & Swell period (s) \\
\hline level & Estimated tide $(\mathrm{m})$ \\
\hline storm3 & Hours since storm with wave height $>3 \mathrm{~m}$ \\
\hline storm4 & Hours since storm with wave height $>4 \mathrm{~m}$ \\
\hline date & Julian date (number of days since January 1, 1960) \\
\hline time & Hours since midnight \\
\hline sea state & Sea state index $(0,0.5,1,1.5,2,2.5)$ \\
\hline overcast & Percent overcast $(\%)$ \\
\hline aircraft & Aircraft type: MI-8 (Helicopter) or AN-28 (Fixed-Wing) \\
\hline aircraft*fog & Interaction between aircraft and fog \\
\hline aircraft*visibility & Interaction between aircraft and visibility \\
\hline aircraft*white_caps & Interaction between aircraft and white_caps \\
\hline aircraft*overcast & Interaction between aircraft and overcast \\
\hline wave period $^{* *}$ & wind wave period (s) \\
\hline $\operatorname{sun}^{* *}$ & Index of sun $(0,0.5,1)$ \\
\hline depth** & Depth $(\mathrm{m})$ \\
\hline b_speed ${ }^{*}$ & Bottom current speed $(\mathrm{mm} / \mathrm{s})$ \\
\hline$b \_$direction* & Bottom current direction (N, E, S, W) \\
\hline u_speed ${ }^{*}$ & Surface current speed $(\mathrm{mm} / \mathrm{s})$ \\
\hline u_direction* & Surface current direction $(\mathrm{N}, \mathrm{E}, \mathrm{S}, \mathrm{W})$ \\
\hline c_speed ${ }^{*}$ & All-depths average current speed $(\mathrm{mm} / \mathrm{s})$ \\
\hline c_direction* & All-depths average current direction (N, E, S, W) \\
\hline$b 2 T 1 *$ & Shoreward distance (meters) from block center to $\mathrm{T} 1$ position \\
\hline $\operatorname{seg} 3 h$ & Sound energy estimate for preceding $3 \mathrm{~h}$ period \\
\hline $\operatorname{seg} 3 d$ & Sound energy estimate for preceding 3 day period \\
\hline aasp3h*** & Average unsigned source aspect for preceding $3 \mathrm{~h}$ period \\
\hline $\operatorname{aasp} 3 d^{* * *}$ & Average unsigned source aspect for preceding 3 day period \\
\hline rubin $3 h^{*}$ & $\begin{array}{l}\text { Position of Rubin relative to block center position in preceding } \\
3 \mathrm{~h} \text { period }\end{array}$ \\
\hline rubin $3 d^{*}$ & $\begin{array}{l}\text { Position of Rubin relative to block center position in preceding } \\
3 \text { day period }\end{array}$ \\
\hline atlas $3 h^{*}$ & $\begin{array}{l}\text { Position of Atlas relative to block center position in preceding } \\
3 \mathrm{~h} \text { period }\end{array}$ \\
\hline $\operatorname{atlas} 3 d^{*}$ & $\begin{array}{l}\text { Position of Rubin relative to block center position in preceding } \\
3 \text { day period }\end{array}$ \\
\hline
\end{tabular}

However, group size was measured consistently during all flights and the response variable was density of whales at the surface. During estimation of $g(x)$, various smoothing functions of $x$ were fit to observed distance data in program DISTANCE and the "best" function was chosen for the final estimate. The uniform, hazard-rate, and half-normal key functions with cosine, simple polynomial, and hermite polynomial series expansions were fit to observed distance data (Buckland et al. 1993). The sightability 
function with lowest Akaike's Information Criterion AIC (Littell et al. 1996) was chosen as the final estimate of the sightability function.

Multiple regression analysis of gray whale densities

The observed densities of western gray whales were analysed by multiple regression to determine whether changes in distribution and abundance were correlated with seismic sound energy after variation explained by other environmental variables had been accounted for. The environmental variables considered are listed in Table 2. Prey availability was not considered due to lack of site specific data at the time. No data were excluded on the basis of weather. In total, 562 and 162 surveys of individual blocks were conducted during
Fig. 2 Histogram of perpendicular distances from the transect line for all gray whale groups sighted from the helicopter (top) and fixed-wing aircraft (bottom) during favorable sighting conditions
Sightings of whales vs. perpendicular distances, helicopter

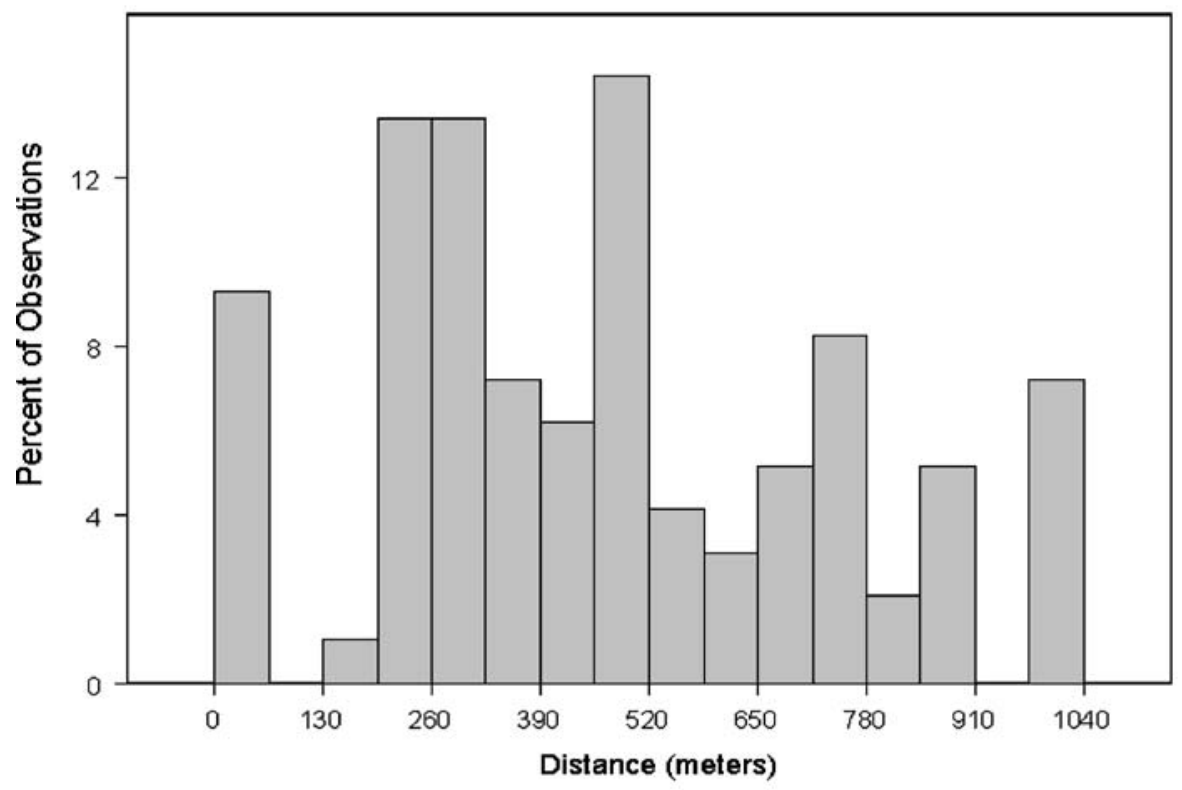

Sightings of whales vs. perpendicular distances, fixed wing An-28

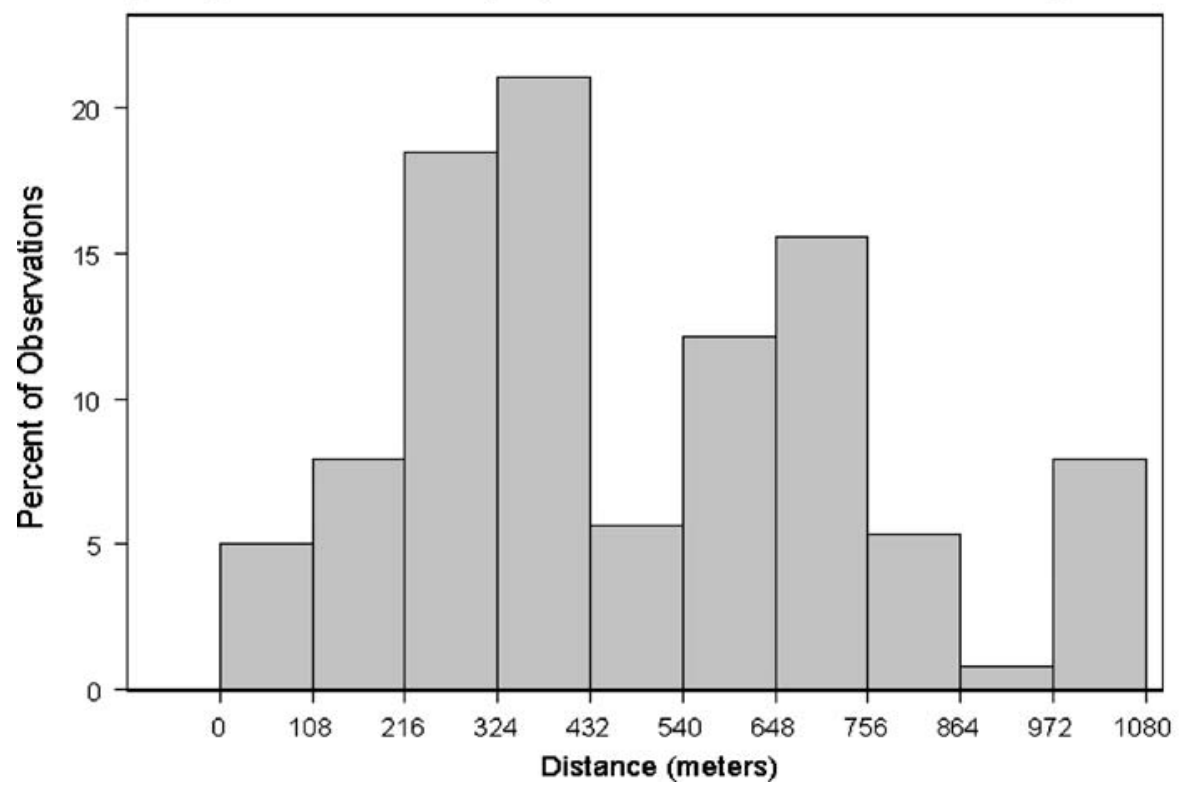


Helicopter - Good Conditions

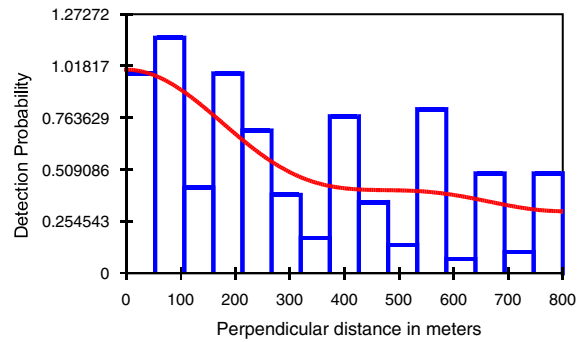

Fig. 3 Histogram of detection distances (perpendicular distances from the transect line) and plot of the estimated sightability functions for helicopter aerial surveys flown under good and poor sightability conditions. Perpendicular distances

favorable and poor conditions, respectively. Gray whale density was estimated using the sightability functions developed separately for favorable and poor conditions and for two aircraft types used in the study.

Estimates of whale density were not normally distributed, because over $50 \%$ were zeros and the distribution of non-zero estimates was highly skewed. Normalizing transformations were not adequate to correct the non-normality problem. Consequently, a quasi-likelihood regression model (McCullagh and Nelder 1989) was adopted that only assumed that the expected value and variance of the number of whale groups observed were finite. Correlation analysis of the variables listed in Table 2 showed multiple examples of collinearity between variables. Where high collinearity was found, one of the variables was removed.

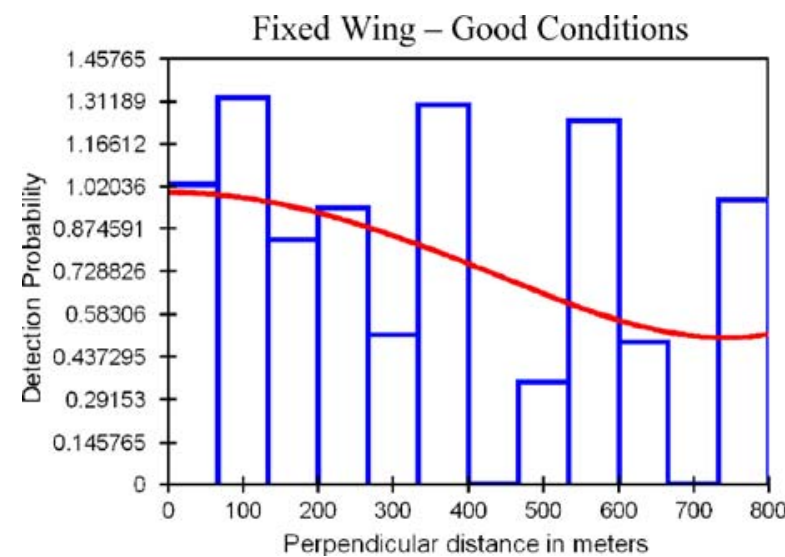

Fig. 4 Histogram of detection distances and plot of the estimated sightability functions for fixed-wing aerial surveys flown under good and poor sightability conditions. Perpendicular distances from the transect line were truncated at $200 \mathrm{~m}$
Helicopter - Poor Conditions

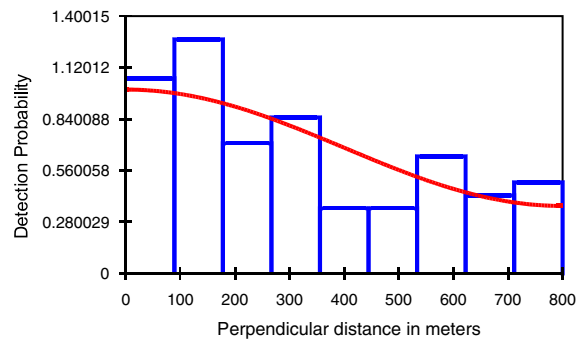

from the transect line were truncated at $200 \mathrm{~m}$ and the remaining distances were shifted to the left by subtracting $200 \mathrm{~m}$. As a result, $0 \mathrm{~m}$ distance in the histogram actually represents a point $200 \mathrm{~m}$ perpendicular to the transect line

The first analysis in the regression modelling process used stepwise variable selection to create a quasi-likelihood model containing significant nuisance variables. During forward steps of the stepwise process, nuisance variables in the list of variables under consideration were added to an existing model one-at-a-time. The statistical significance of each added variable was determined by the quasi-likelihood approximate $F$ tests (McCullagh and Nelder 1989). During forward steps, the variable with the smallest $p$ value was retained in the model, provided the smallest $p$ value was less than or equal to $\alpha=0.05$. Following each forward step, a backward 'look' was taken, in which the significance of all variables already in the model was re-assessed using approximate $F$ tests. During backward looks, the variable with the greatest $p$ value was eliminated, provided its $p$ value was

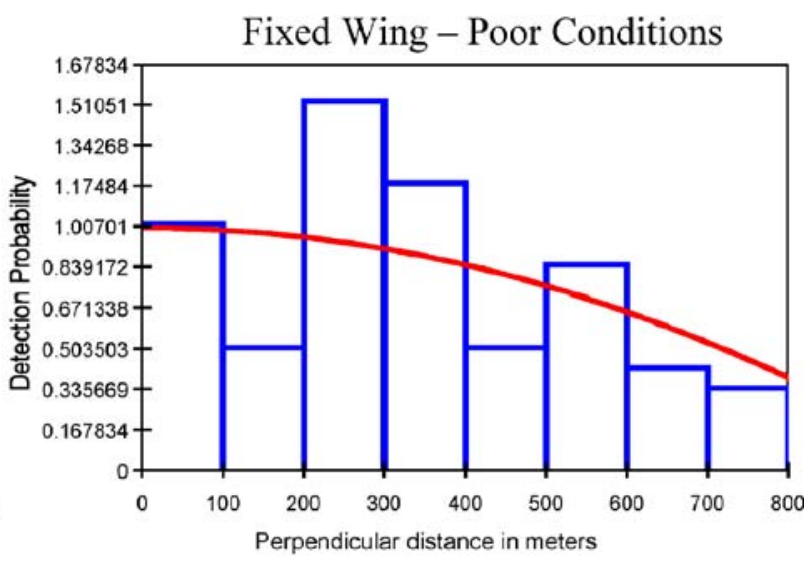

and the remaining distances were shifted to the left by subtracting $200 \mathrm{~m}$. As a result, $0 \mathrm{~m}$ distance in the histogram represents a point $200 \mathrm{~m}$ perpendicular to the transect line 
Fig. 5 Average group size of whales before, during and after the Odoptu seismic survey in 2001. Data from helicopter and fixed wing aircraft are combined

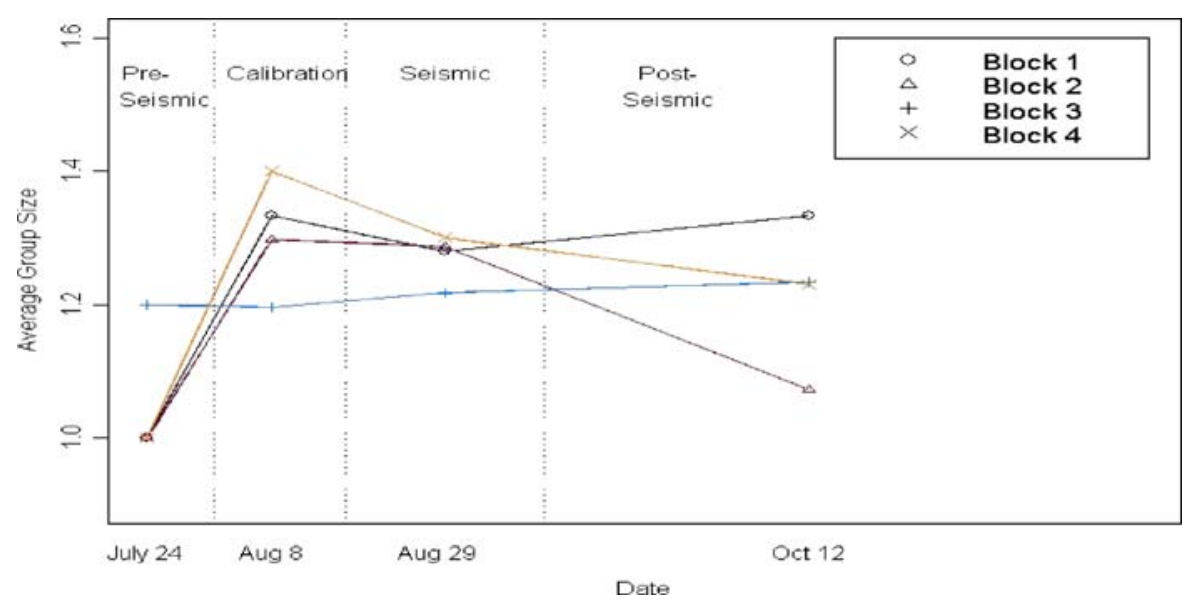

greater than $\alpha=0.05$. This process continued until no variables significantly contributed to the model during a forward step, and no variable was eliminated through iteration.

To aid interpretation of the model, the predicted average number of gray whales in each block within $1 \mathrm{~km}$ of line 1 was computed twice for each survey. The first prediction utilized the estimated level of accumulated received seismic survey sound energy at each block (i.e., estimated levels of seg $3 h$ or seg3d (Gailey et al. 2007)). The second prediction assumed received survey sound level estimates equaled zero (i.e., no seismic survey sound). For both predictions, weather was assumed to be ideal and all weather and sea state variables in the final model were set to their most favorable levels. The difference between these two predictions was an estimate of the number of additional or missing whales associated with positive levels of received sound energy. Both predictions were plotted against time to illuminate the periods of discrepancies between the two estimates.

See "Appendix" for details of the methodology utilized in the quasi-likelihood regression analysis.

\section{Results}

\section{Survey effort}

During the 156-day study period (19 July-19 November) 90 aerial surveys of the sampling grid were conducted, and a total of 499 gray whale groups were observed in blocks 1-4 along lines 1 and 2 .
Sightability calculations

The histograms of gray whale sightings as a function of perpendicular distance from the line for both aircraft types indicated that all whales on-transect line were not detected (Fig. 2). For both aircraft types, reduced sightability near the line due to the visual obstruction by the aircraft was remedied by assuming that all whales at the surface at $200 \mathrm{~m}$ from the line were detected, and deleting all sightings at distances less than $200 \mathrm{~m}$. The truncated line was then shifted $200 \mathrm{~m}$ inward toward the line and line half-widths of $1,000 \mathrm{~m}$ became $800 \mathrm{~m}$ for both aircraft. Wilcoxon and Kruskal-Wallis tests showed that under good sightability conditions, there was no significant effect of environmental conditions on whale sightability as a function of distance from line. However, under both good and poor sightability conditions, sightability declined with distance from the aircraft (Figs. 3, 4).

Akaike's Information Criterion (AIC) provides a quantitative method for testing how well a model fits the data (see Buckland et al. 1993). The model with the best fit has the lowest AIC value. The best fitting sightability function for helicopter lines (Fig. 3) was a uniform key with cosine series expansion under both good and poor sighting conditions ( $\mathrm{AIC}=3,032.5$ for good conditions; $\mathrm{AIC}=1,154.3$ for poor conditions). The best fitting sightability function for fixed-wing aircraft (Fig. 4) was a uniform key with simple polynomial series expansion under both good and poor sighting conditions (AIC $=4,436.3$ for good conditions; $\mathrm{AIC}=1,000.0$ for poor conditions). Estimates of $f(0)$ were 0.0023 for helicopter lines flown under 
Table 3 Coefficients, standard errors, 95\% confidence intervals, test-statistics, and $p$ values in the final quasi-likelihood regression model

\begin{tabular}{|c|c|c|c|c|c|c|c|c|c|}
\hline \multirow[t]{2}{*}{ Parameter } & \multirow[t]{2}{*}{$d f$} & \multirow[t]{2}{*}{ Estimate } & \multirow[t]{2}{*}{ Standard error } & \multicolumn{2}{|c|}{$95 \%$ confidence interval } & \multicolumn{2}{|l|}{$\chi^{2}$} & \multicolumn{2}{|c|}{ Approximate $F$} \\
\hline & & & & Lower limit & Upper limit & Statistic & $p$ value & $F$ & $p$ value \\
\hline intercept & 1 & 268.6124 & 37.9992 & 194.1353 & 343.0895 & 49.9700 & $<0.0001$ & & \\
\hline line $=1$ & 1 & 1.0558 & 0.1101 & 0.8399 & 1.2716 & 91.900 & $<0.0001$ & 107.50 & $<0.0001$ \\
\hline block $=1$ & 1 & 0.6590 & 0.2044 & 0.2584 & 1.0596 & 10.400 & 0.0013 & & \\
\hline block $=2$ & 1 & 0.8375 & 0.1948 & 0.4556 & 1.2194 & 18.4800 & $<0.0001$ & 7.02 & 0.0001 \\
\hline block $=3$ & 1 & 0.6284 & 0.2049 & 0.2268 & 1.0300 & 9.4100 & 0.0022 & & \\
\hline white_cap $=0$ & 1 & 0.7884 & 0.3643 & 0.0744 & 1.5023 & 4.6800 & 0.0305 & & \\
\hline white_cap $=0.5$ & 1 & 0.2702 & 0.4381 & -0.5885 & 1.2190 & 0.38 & 0.5374 & 6.23 & $<0.0001$ \\
\hline white_cap $=1$ & 1 & 0.2720 & 0.3723 & -0.4576 & 1.0016 & 0.53 & 0.465 & & \\
\hline white_cap $=1.5$ & 1 & -0.6843 & 0.6594 & -1.9766 & 0.6080 & 1.08 & 0.2993 & & \\
\hline date_loc & 1 & -0.0189 & 0.0025 & -0.0238 & -0.0140 & 57.07 & $<0.0001$ & 62.21 & $<0.0001$ \\
\hline$f \circ g=0$ & 1 & 0.4506 & 0.4616 & -0.4541 & 1.3552 & 0.95 & 0.329 & 4.06 & 0.0179 \\
\hline$f \circ g=1$ & 1 & -0.2593 & 0.5368 & -1.3114 & 0.7928 & 0.23 & 0.629 & & \\
\hline wave_height & 1 & -0.2288 & 0.0621 & -0.3505 & -0.1071 & 13.58 & 0.0002 & 13.76 & 0.0002 \\
\hline $\operatorname{seg} 3 d$ & 1 & $-3.64 \mathrm{E}-23$ & $6.66 \mathrm{E}-23$ & $-1.67 \mathrm{E}-22$ & $9.42 \mathrm{E}-23$ & 0.3 & 0.5852 & 0.11 & 0.074 \\
\hline seg3 $d^{*}$ blockl & 1 & 2.31E-22 & $2.05 \mathrm{E}-22$ & $-1.71 \mathrm{E}-22$ & $6.33 \mathrm{E}-22$ & 1.27 & 0.2598 & 3.29 & 0.0268 \\
\hline seg $3 d^{*}$ block 2 & 1 & $3.40 \mathrm{E}-23$ & $6.95 \mathrm{E}-23$ & $-1.02 \mathrm{E}-22$ & $1.70 \mathrm{E}-22$ & 0.24 & 0.6251 & & \\
\hline $\operatorname{seg} 3 d^{*}$ block 3 & 1 & $-4.99 \mathrm{E}-23$ & $7.00 \mathrm{E}-23$ & $-1.87 \mathrm{E}-22$ & $8.72 \mathrm{E}-23$ & 0.51 & 0.4756 & & \\
\hline
\end{tabular}

good sighting conditions, 0.0016 for fixed-wing aircraft flown under good sighting conditions, 0.001573 for helicopter lines flown during poor conditions, and 0.00183 for fixed-wing aircraft flown during poor conditions.

Expected whale group size $(\widehat{E}(s)$ in Eq. 1) was estimated by calculating mean group size in each

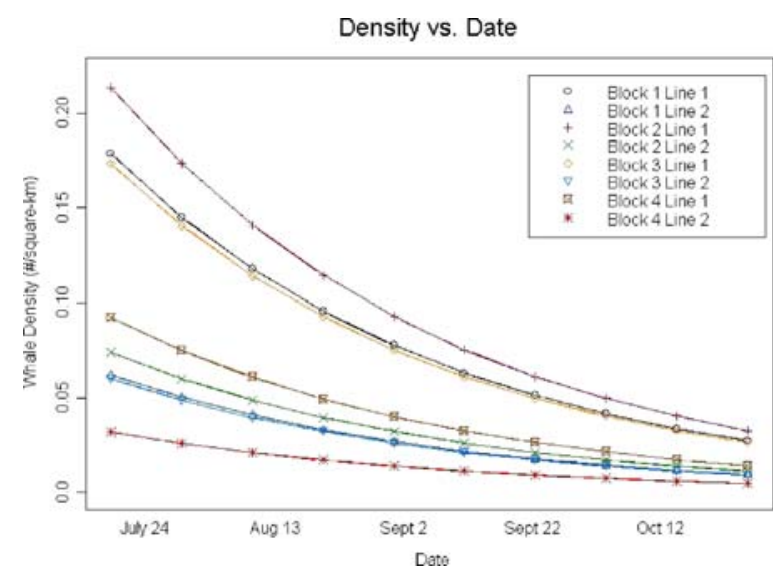

Fig. 6 Plot of predicted gray whale density as a function of date (calendar date). All other variables in the final model ( $f o g$, white_cap, wave_height, seg3d) were held constant at their median values block during each period. Combining data from two aircraft types and two sighting conditions, average group size per period in each block varied from 1.0 to 1.4 (Fig. 5). Average group size was calculated separately for each aircraft to guard against introducing a potential source of bias.

Quasi-likelihood multiple regression analysis

The environmental variables selected by the stepwise regression procedure contained effects for line, block, date, white_cap, fog, and wave_height. Seismic survey-related variables that were fitted to the model included estimates of total accumulated sound energy at the $\mathrm{T} 1$ point (see below for an explanation of $\mathrm{T} 1$ point) during the 3-h (seg3h) and 3-day (seg3d) period preceding an aerial survey, average unsigned aspect of the seismic survey airgun array to the T1 point during the preceding 3-h and 3-day period (aasp3h, aasp3d), and positions of the support vessels $\mathrm{m} / \mathrm{v}$ Rubin and $\mathrm{m} / \mathrm{v}$ Atlas relative to the area's center for the preceding 3-h and 3-day period (rubin3h, rubin3d, atlas $3 h$, atlas $3 d$ ). All seismic survey-related variables except one did not have statistically significant correlation with the distribution and abundance 


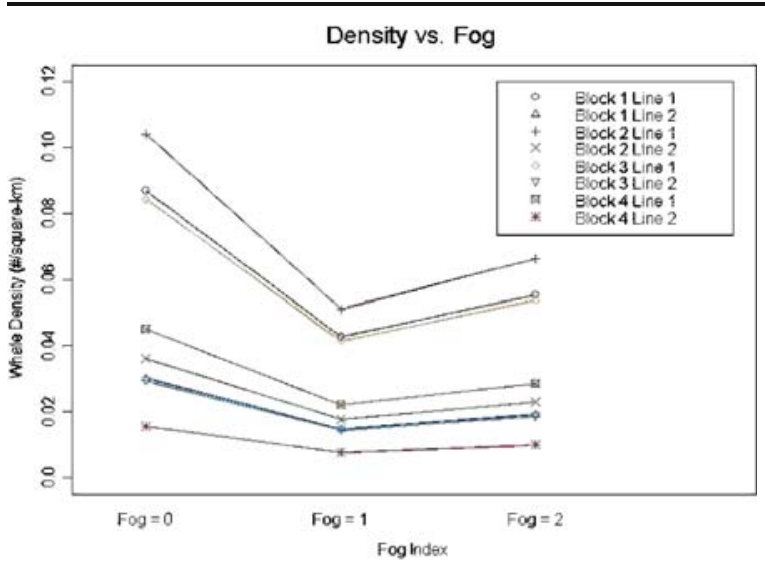

Fig. 7 Plot of predicted gray whale density as a function of fog. All other variables in the final model (date, white_cap, wave height, seg $3 d$ ) were held constant at their median values. $F o g=0$ (no fog); $f \circ g=1$ (light fog/haze), $f \circ g=2$ (dense fog)

of whales. Total estimated seismic survey sound energy levels received during the previous 3-day period $(\operatorname{seg} 3 d)$ and associated interaction with survey block explained a small but statistically significant amount of residual variation when added to the environmental variable model. The final model of the primary analysis of average density is given in Eq. 3;

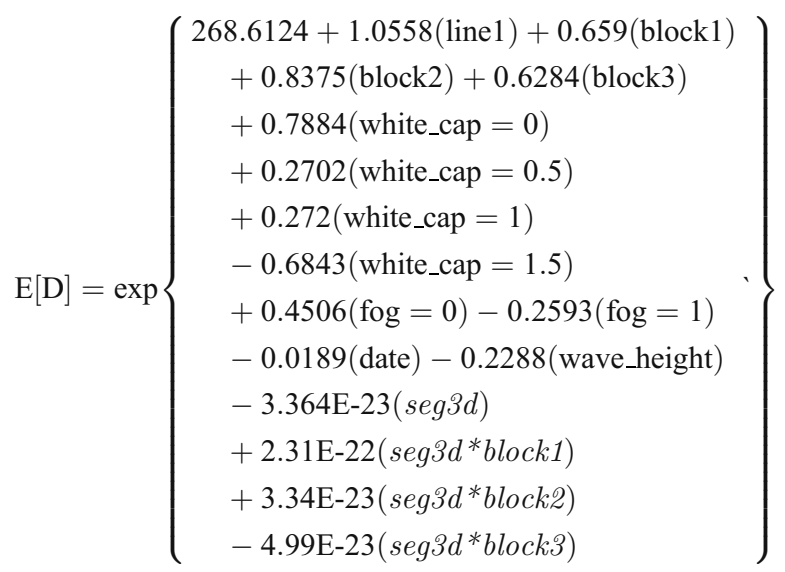

Standard errors, 95\% confidence intervals, and significance of each term in the final model are listed in Table 3. Temporal autocorrelation in residuals of the final model that were close in time (several hours to 1 day apart) was positive but not large enough to adversely effect model estimates and $p$ values

Density vs. White Cap Index

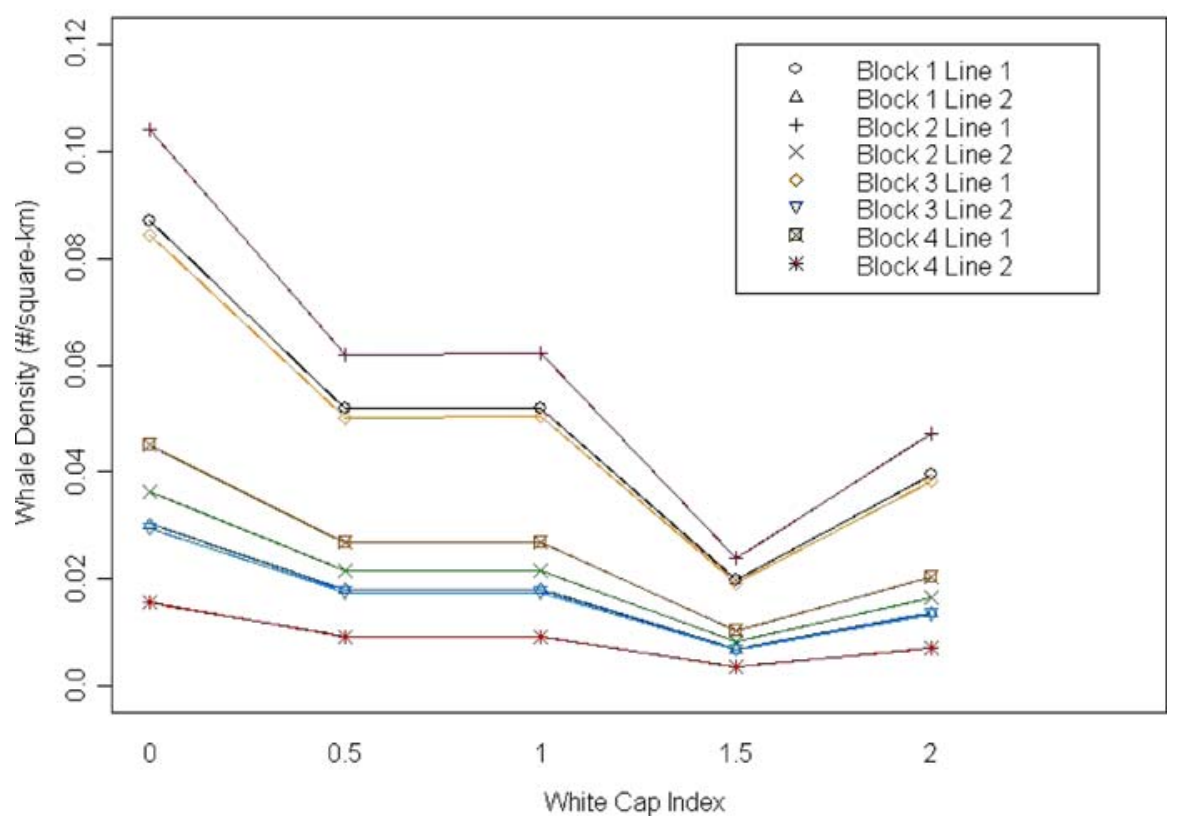

Fig. 8 Plot of predicted gray whale density as a function of white_cap. All other variables in the final model (date, fog, wave_height, seg3d) were held constant at their median values.
White cap index varies from 0 (no white caps) to 1 (sparse white caps that do not mask whales) to 2 (numerous white caps, masking whales and hampering observation) 
Fig. 9 Plot of predicted gray whale density as a function of wave_height (meters). All other variables in the final model (date, fog, white_cap, seg $3 d$ ) were held constant at their median values
Density vs. Wave Height

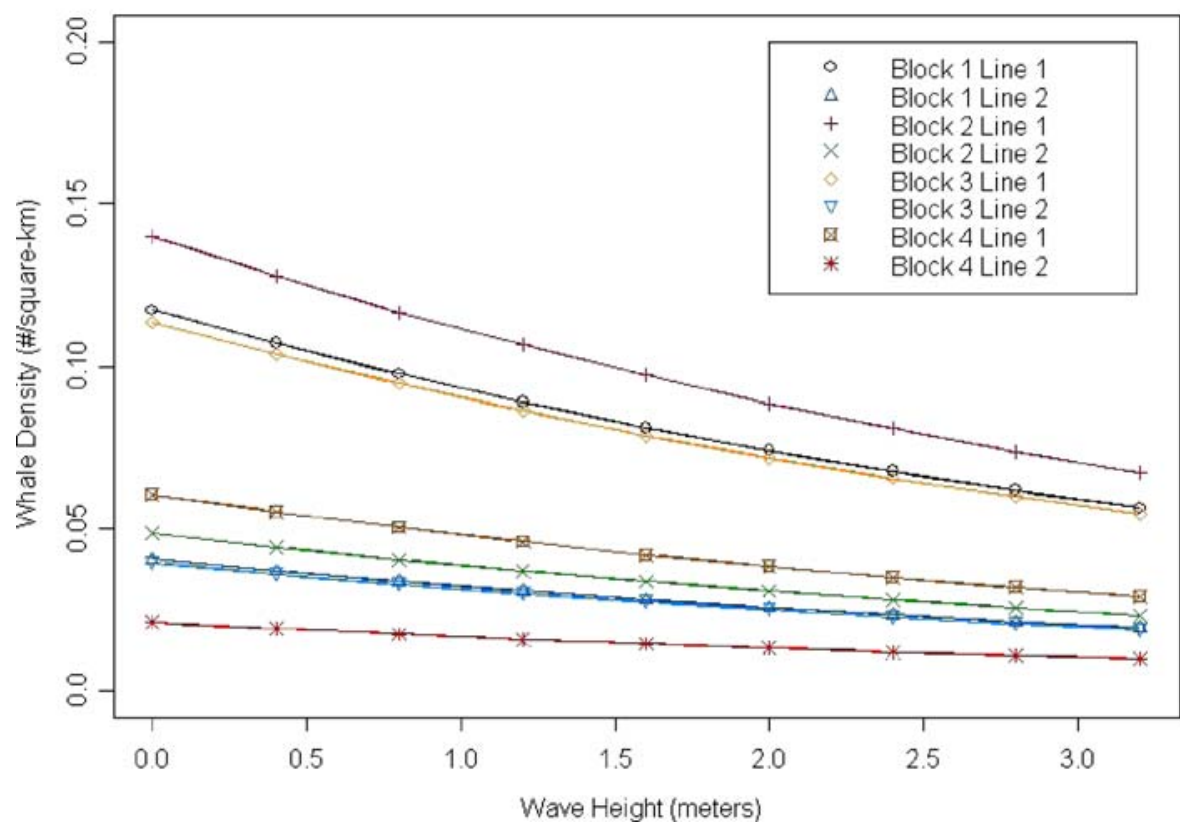

(Moran's $I=0.255,95 \% \mathrm{CI}=0.158$ to 0.352 ). Spatial autocorrelation was not deemed important because of the large size of the blocks.

In the environmental part of the final model, density of whales was estimated to be 2.87 times higher on line 1 than on line 2 . There was a predicted $2 \%$ decline in average density every day of the study. During the 156-day study period, the predicted density in blocks 1,2 , and 3 on line 1 declined by $\sim 75 \%$ (Fig. 6). To illustrate the size of the effects of variables in the final model, plots showing predicted whale density as a function of each variable are shown in Figs. 7, 8, 9 and 10. For each plot all other variables in the final model were held constant at their median or most common values. Predicted density declined by $\sim 57 \%$ when fog index was 1 (light fog) compared with surveys when fog index was 0 (no fog) (Fig. 7). Predicted density in blocks 1, 2, and 3 on line 1 declined by $\sim 65 \%$ when white_cap index was 1.5 compared to times when white_cap index was zero (Fig. 8). Overall, environmental variables explained a large proportion of the total variation in the data
Fig. 10 Boxplots of estimated total sound energy during preceding 3-day pe$\operatorname{riod}(\operatorname{seg} 3 d)$ for each of the block*line combinations. The shaded box is the interquartile range (i.e., 25 $75 \%$ ) and the smaller white box represents the median. The brackets represent two interquartile ranges, and the lines (whiskers) indicate individual extreme values

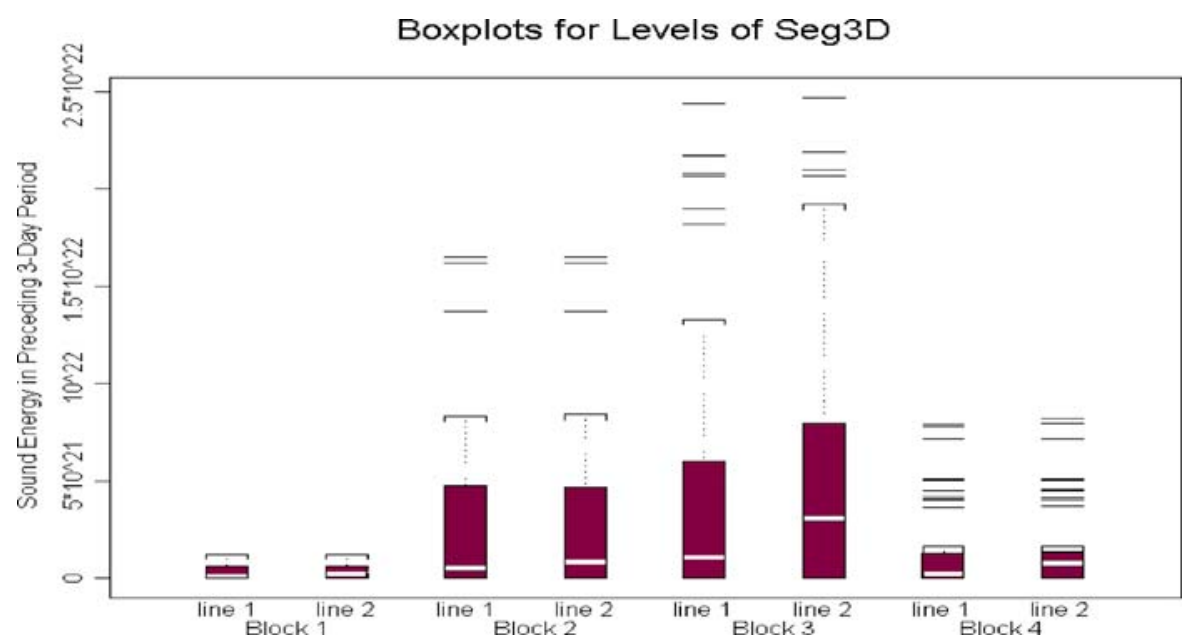


Fig. 11 Plot of predicted gray whale density as a function of estimated seismic survey sound energy $(\operatorname{seg} 3 d)$ for the preceding 3day period. All other variables in the final model (fog, white_cap, wave_height, date) were held constant at their median values

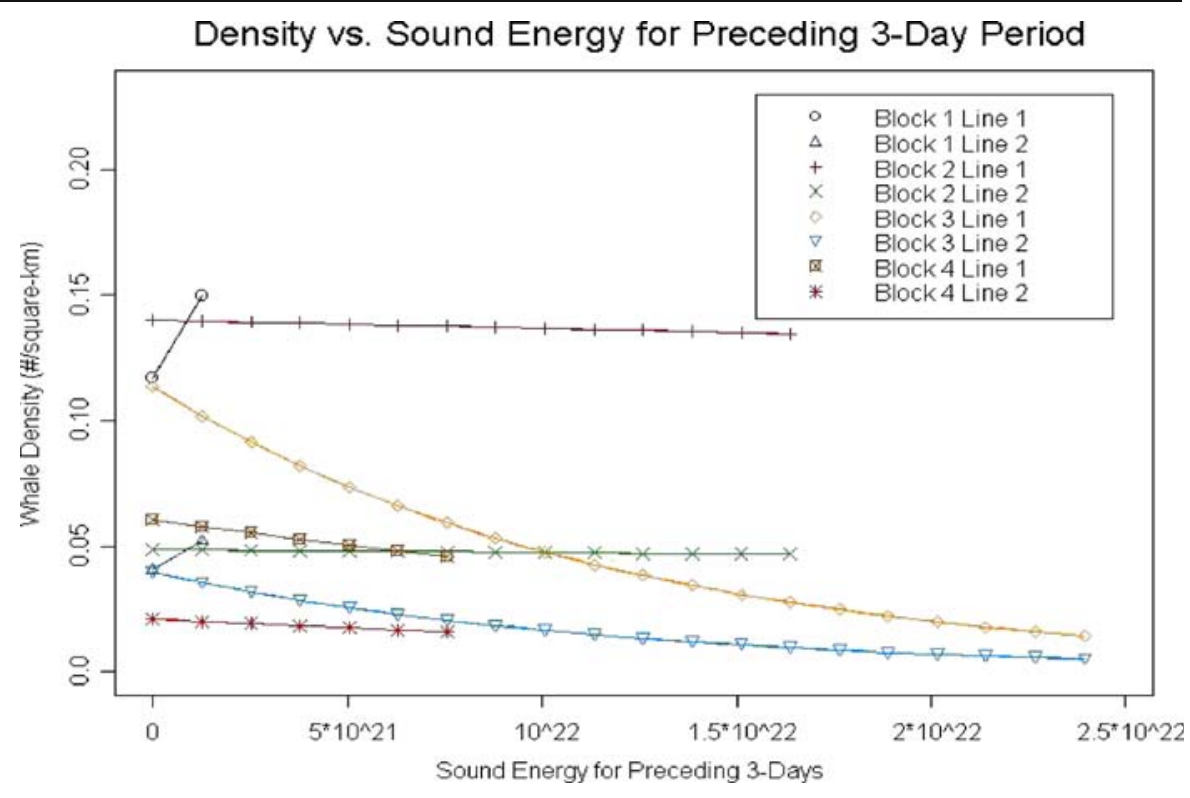

(Table 3). $F$ values are highest for line $(F=107.5)$, date $(F=62.2)$, and wave height (Fig. 9) $(F=13.8)$.

Boxplots of $\operatorname{seg} 3 d$ for each block-by-line combination are shown in Fig. 10. Figure 14 shows a decrease in whale density on block 3 (lines 1 and 2) when estimated seismic survey sound energy increased. Figures 11 and 12 show an increase in predicted whale density on block 1 when estimated seismic survey sound energy increased. Estimated seismic survey sound levels were low on block 1: maximum estimated seg3d was circa 20 times lower on block 1 than on block 3 (Figs. 10, 11). Predicted whale density did not change on blocks 2 and 4 with the increase of estimated seismic survey sound energy (Figs. 11, 13 and 15). See Appendix for the explanation of Figs. 11, 13, 14 and 15.

Residual plots used to assess the goodness-of-fit of the final model are shown in Figs. 16, 17, 18
Fig. 12 Predictions of average number of whales in the area of block 1 of transect 1 based on the estimated seismic survey sound energy $(\operatorname{seg} 3 d)$ and zero sound energy. All other variables in the final model (fog, white_cap, wave_height) were held constant at their optimum levels (zero fog, white_cap, and wave_height). The shaded area represents the 95\% confidence band for the predicted number of whales at the estimated sound energy level

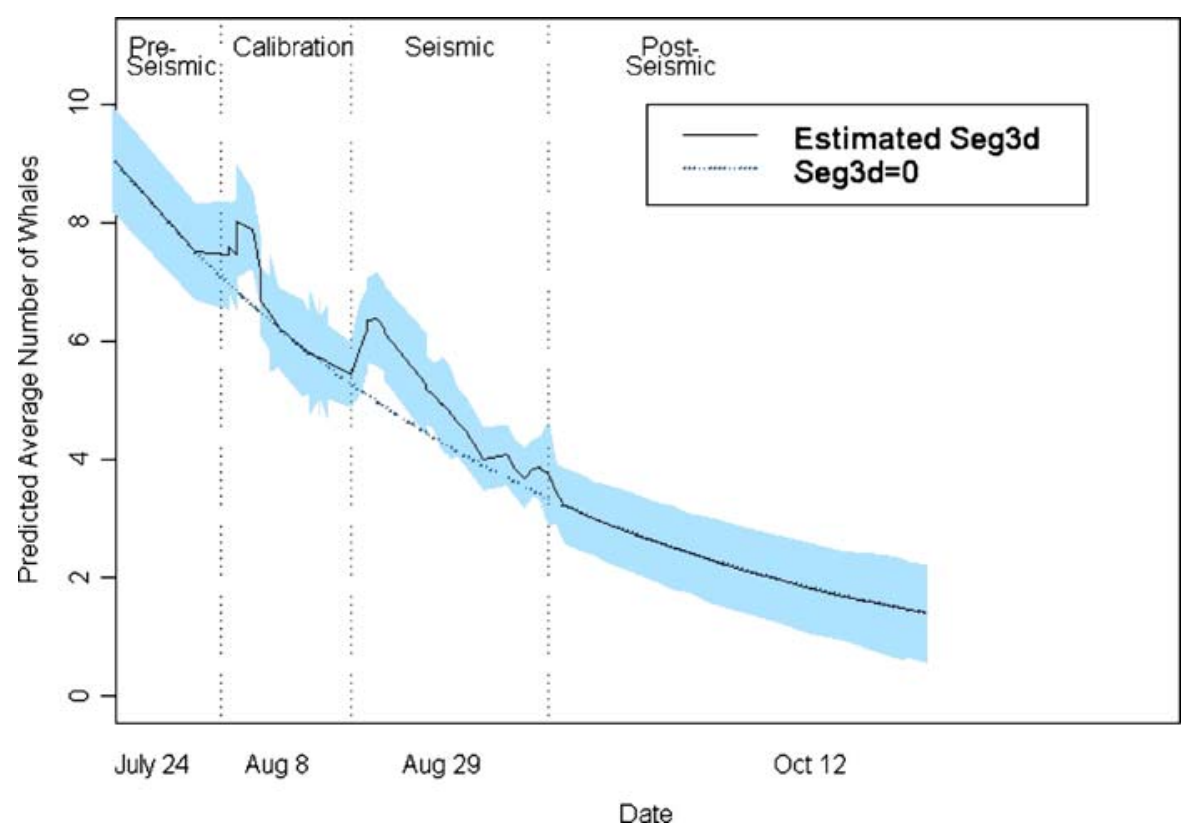


Fig. 13 Predictions of average number of whales in the area of block 2, line 1 based on the estimated sound energy (seg3d) and zero sound energy. All other variables in the final model (fog, white_cap, wave_height) were held constant at their optimum levels (zero). The shaded area represents the $95 \%$ confidence band for the predicted number of whales at the estimated sound energy level

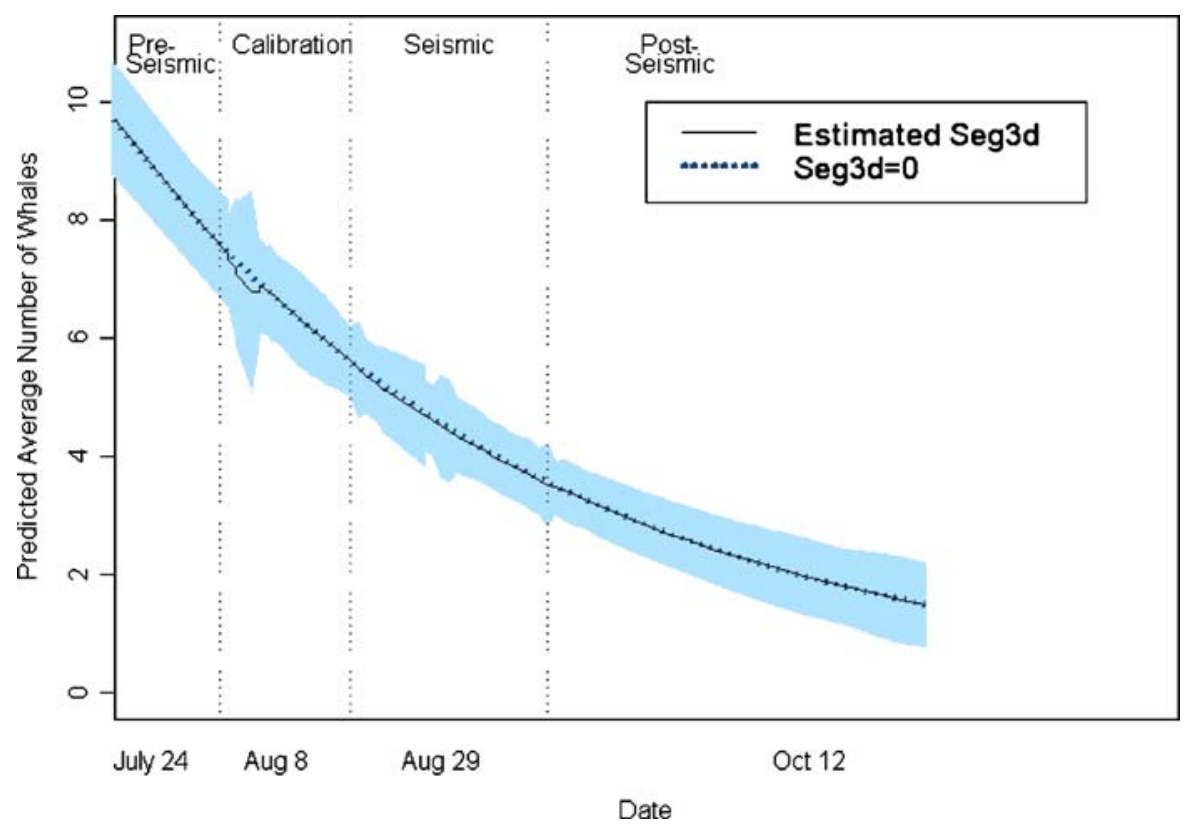

and 19. Surveys conducted during poor weather conditions are marked in these plots to assist assessment of model fit at these times. A few large under-predictions (predicted density lower than observed density) were observed on block 1 during the end of the calibration survey. A few large over-predictions were observed on block 1 during the middle calibration survey and early seismic survey. During the middle of the seismic survey, predicted densities on block 1 were lower on average than observed densities, while during the early part of the post-seismic survey, predictions on block 1 were higher on average than observed densities. A similar pattern was observed in the residuals from block 2. Although there existed a couple of large under-predictions on block 3 , residuals from blocks 3 and 4 generally appeared to be randomly distributed through time and did not display systematic departures from zero (Figs. 18, 19).
Fig. 14 Predictions of average number of whales in the area of block 3 , line 1 based on the estimated sound energy $(\operatorname{seg} 3 d)$ and zero sound energy. All other variables in the final model (fog, white_cap, wave_height) were held constant at their optimum levels (zero). The shaded area represents the $95 \%$ confidence band for the predicted number of whales at the estimated sound energy level

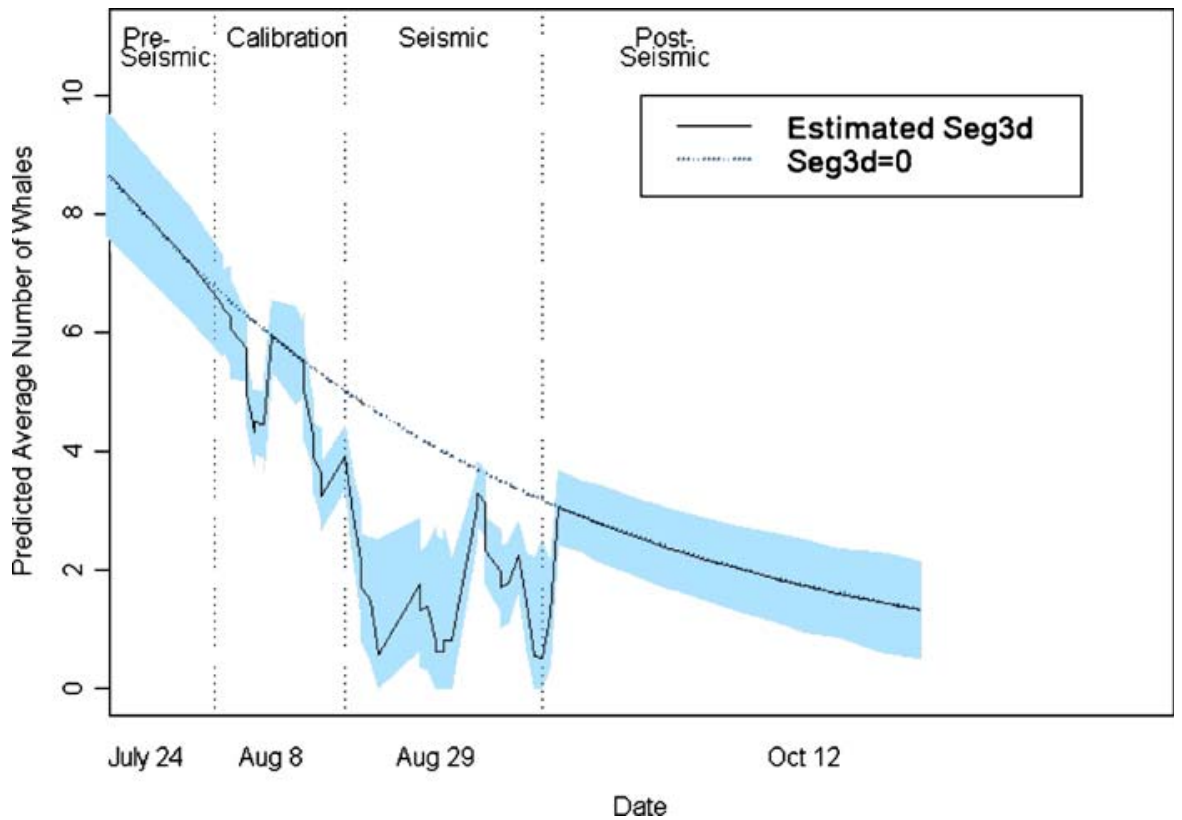


Fig. 15 Predictions of average number of whales in the area of block 4, line 1 based on the estimated sound energy (seg3d) and zero sound energy. All other variables in the final model (fog, white_cap, wave_height) were held constant at their optimum levels (zero). The shaded area represents the $95 \%$ confidence band for the predicted number of whales at the estimated sound energy level

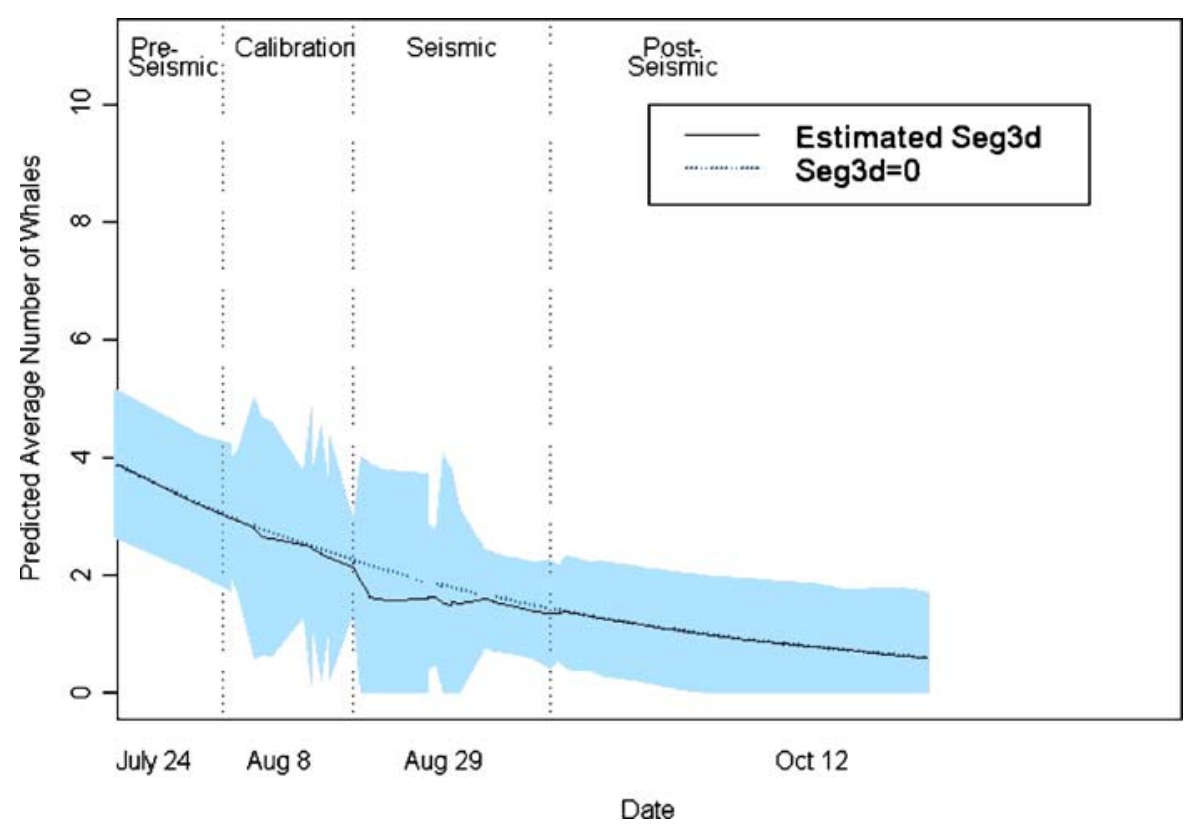

\section{Discussion}

This study was designed to determine if western gray whale distribution and abundance in their feeding habitat (Piltun feeding area) were affected by the 2001 Odoptu seismic survey. The objectives of the study were (a) to determine if gray whales were displaced out of their feeding habitat; (b) to assess temporal changes in distribution and abundance of gray whales during the seismic survey, and (c) to assess the influence of the seismic survey, environmental factors, and other variables on the distribution and

\section{Block 1 Residuals}

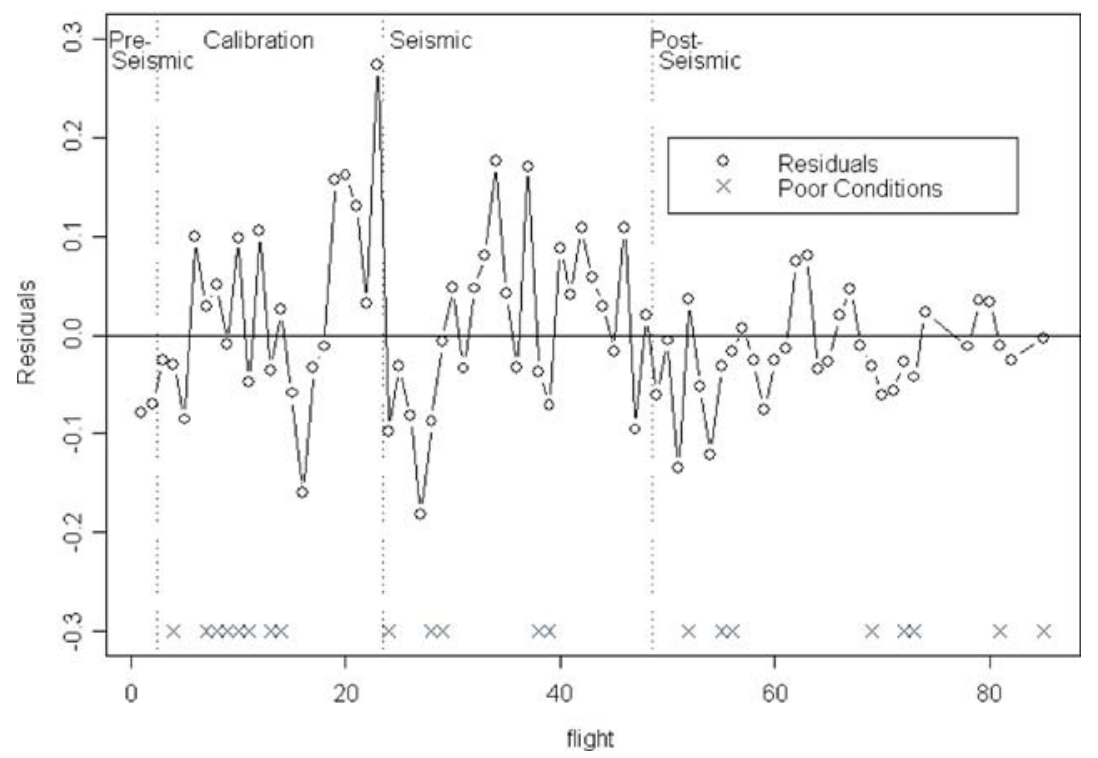

Fig. 16 Residuals (observed vs. predicted) for the average density of gray whales, based on each flight over block 1 (lines 1 and/or 2). Predictions were based on the final model for gray whale density. Flights during poor sighting conditions are noted by an $\mathrm{X}$ at the bottom of the plot. See "Estimating gray whale densities" for explanation of poor sighting conditions 


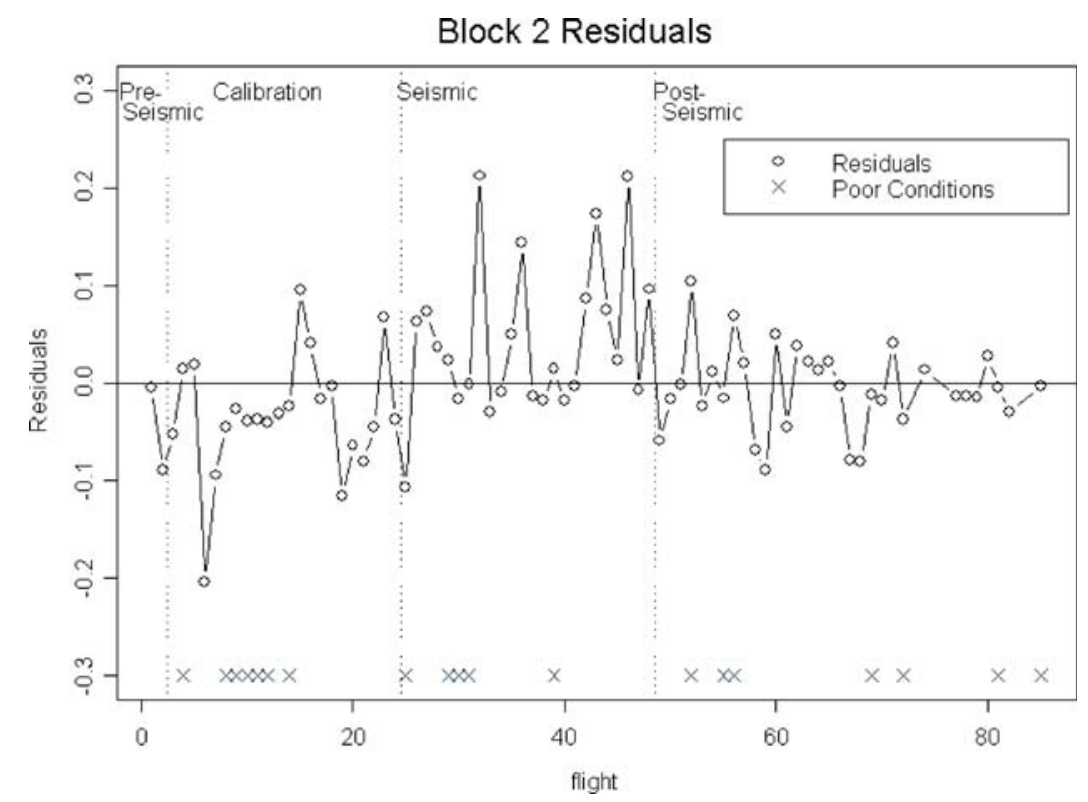

Fig. 17 Residuals (observed vs. predicted) for the average density of gray whales based on each flight over block 2 (transects 1 and/or 2). Predictions were based on the final model for gray whale density. Flights during poor sighting conditions are noted by an $\mathrm{X}$ at the bottom of the plot. See "Estimating gray whale densities" for explanation of poor sighting conditions

several times during the seismic survey. Our findings indicate that the overall number of whales observed within the Piltun feeding area during the seismic survey remained stable (Fig. 23; Yazvenko et al. 2002). No whales were observed outside their feeding grounds during broad-scale aerial surveys, which indicates that no shift occurred from Piltun feeding area into adjacent habitat (Fig. 22; Yazvenko et al. 2002; Blokhin et al. 2002).

To address objectives (b) and (c), aerial survey data were analysed using quasi-likelihood multiple regression, which aimed to assess the correlation of both environmental and seismic survey-related variables with densities of gray whales in various parts of the feeding area, and model the number of whales potentially displaced by the seismic survey. We found a decrease in the number of observed whales on block 3 (Figs. 1, 23) and a corresponding increase on block 1 , which indicates that the distribution of two to four whales observed on the surface may have shifted during the seismic survey. Availability of gray whales (Buckland et al. 1993) was estimated to be $\sim 45 \%$ in this study (Muir, LGL Limited, unpublished data); therefore, a total of about five to ten gray whales may have been displaced by the seismic survey. 
Fig. 19 Residuals (observed $v s$. predicted) for the average density of gray whales based on each flight over block 4 (lines 1 and/or 2). Predictions were based on the final model for gray whale density. Flights during poor sighting conditions are noted by an $\mathrm{X}$ at the bottom of the plot. See "Estimating gray whale densities" for explanation of poor sighting conditions

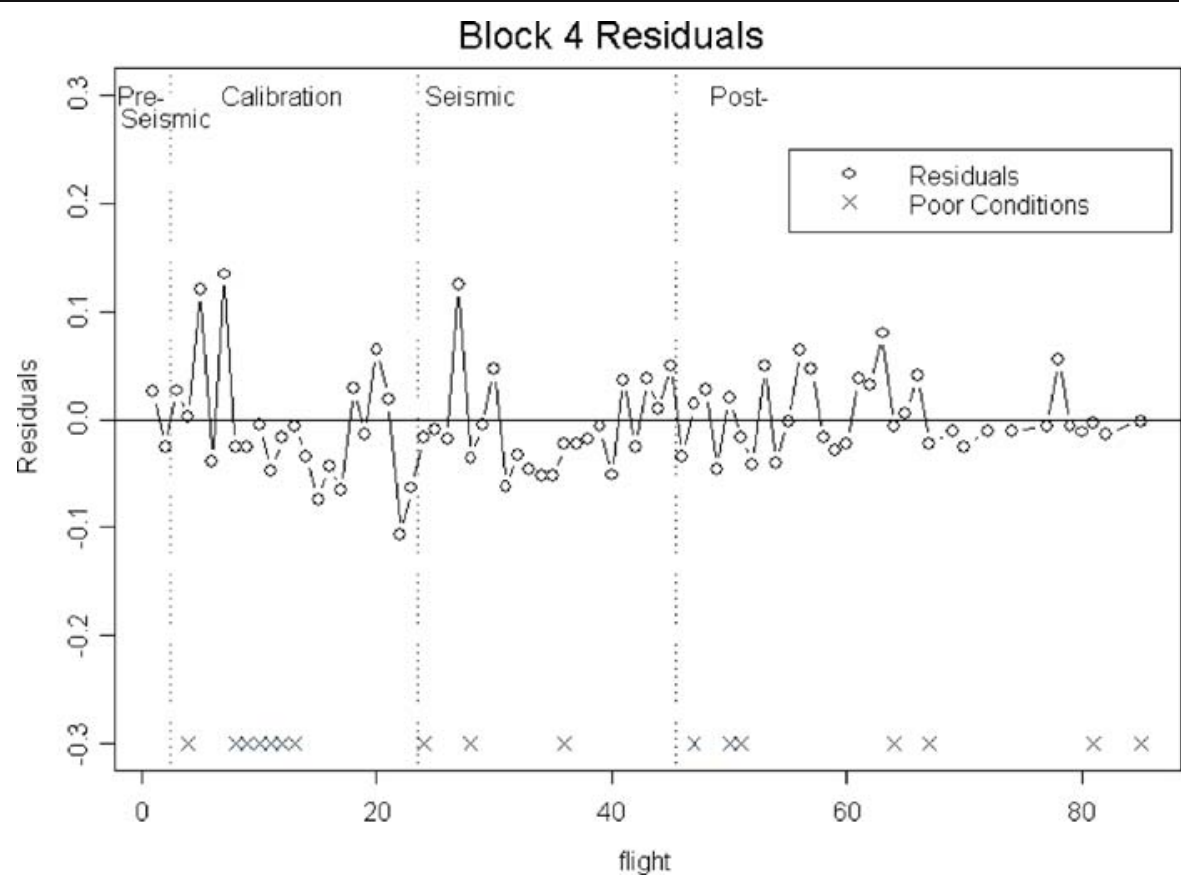

Quasi-likelihood multiple regression analysis

Sightability calculations, as measured by estimated distance functions, were stratified by aircraft type and sighting conditions. Sighting conditions (good and poor) were defined to be amalgamated functions of visibility, white cap index, fog, and sea state. The fact that some of these same variables, viz., white cap index, fog, and sea state, also appear in the final quasilikelihood regression is not illogical. Following standard distance analysis practices, our adjustment for sightability included a single constant (i.e., $\widehat{f}(0)$ ) in the offset of the quasi-regression model that represented an average sightability for whales in one of the four sightability strata. This constant (and average group size) converted number of sightings into density, and density is an intuitive and widely reported response for cetacean aerial surveys. However, this average sightability constant did not and could not account for variation in sightability of individual whales around this average. Inclusion of sightability variables in the quasi-likelihood model did account for variation in sightability of individuals and made a further sightability adjustment because these variables were measured on every sighted whale. The inclusion of these sightability variables in the final quasilikelihood model accounted for a larger proportion of variability in the empirical data than what would have been obtained by including $\widehat{f}(0)$ only.

Environmental and other variables unrelated to the seismic survey explained a large proportion of the total variation in the data (Table 3), with the domination of line and date. $F$ values were highest for line $(F=$ $107.5)$, date $(F=62.2)$, and wave height $(F=13.8$; Fig. 9). Line number is a proxy for water depth related to distance from shore. Peak densities of gray whales were at a depth of $\sim 12 \mathrm{~m}$ (Yazvenko et al. 2002), which is similar to the depth along most of line 1 . Density was estimated to be 2.87 times higher on line 1 than on line 2 that was close to the outer edge of the Piltun feeding area. The significance of date is the result of a seasonal decline in whale densities from maximum to minimum values over time. During the study period, the predicted density of whales in blocks 1,2 , and 3 on line 1 declined by $\sim 75 \%$. Wave height as a proxy of the general sea condition affected sightability of whales to the extent that most observations were considered useless and were suspended at sea state 4 or more (Beaufort scale).

It is necessary to hold environmental parameters constant to understand variation in whale distribution and abundance due to natural effects and, therefore, delineate the effect of seismic survey activities on western gray whales. However, any model is a limited 
tool, which describes some data better than others. One limitation of this technique is the intrinsic inability to distinguish between two or more co-varying effects.

Received seismic survey sound energy accumulated over 3-h period ( $\operatorname{seg} 3 h)$ was not significantly correlated with whale densities. This is an indication of the absence of a sudden ("flight") reaction among whales exposed to seismic survey. A companion behavioral study failed to observe sudden or drastic changes in gray whale behavior correlated with estimated seismic sound levels (Würsig et al. 2002; Gailey et al. 2007).

The average unsigned aspect of approaching seismic survey source vessel (aasp3h, aasp3d) was not correlated with whale densities, nor were the positions of support vessels (Rubin and Atlas). The one variable that was significantly (negatively) correlated with whale density on block 3 was cumulative seismic survey sound energy over the 3 days prior to a survey $(\operatorname{seg} 3 d)$. The model predicted on average $2-4$ fewer observed gray whales (i.e., about 5-10 fewer total whales) on block 3 during surveys when sound energy was highest vs. periods of no seismic survey activities.

The model also indicated that the number of whales on block 1 and possibly block 2 increased during times of high seismic survey sound energy, suggesting that at least some whales relocated southward within the Piltun feeding area. However, the increase in the number of whales predicted by the quasi-likelihood model in blocks 1 and 2 is not large enough to account for two to four whales observed on the surface, which the model predicted to have left block 3 . The reason for this under-estimation is probably a combination of one or more of the following factors:

1. Sound levels on block 3 were not independent of the distribution of whales in that block because mitigation measures were implemented in the vicinity of whales.

2. The shift of some whales south of block 3 may have been caused by factors unrelated to the seismic sur vey, e.g., food availability.

3. A relatively poor fit between the model and the data in blocks 1 and 2 (Figs. 17, 18);

These factors are discussed in more detail below.

1. One of the assumptions of the model used in this analysis was that the location of the source of seismic survey sound (seismic vessel) was an independent variable, whereas the distribution of whales was a dependent variable. This assumption was likely violated, as the mitigation protocol required that the seismic survey source vessel (Nordic Explorer) did not come closer than the buffer distance to gray whales observed in this area, relative to the planned seismic survey line to be surveyed (sail line). Furthermore, seismic surveys did not commence in an area adjacent to feeding gray whales unless buffer distance around the sail line was found to be whale-free during aerial overflights and support vessel surveys, i.e., seismic surveys did not commence unless the sail line was at a greater distance from the whales than the buffer distance, which was $4-5 \mathrm{~km}$ during the seismic survey (Johnson et al. 2007).

2. The shift of some whales south of block 3 may have been caused by unstudied factors unrelated to the seismic survey, such as the availability and distribution of food (Yazvenko et al. 2007). Suitable food availability data for the Piltun area for 2001 are not available (Fadeev 2002).

3. A relatively poor fit between the model and data from blocks 1 and 2 could be due to either inaccuracies in the measured variables or the absence of data for other important variables. The model under-predicts density on several surveys on block 1 at the end of the calibration survey and in the middle of the seismic survey. Averaging the residuals for all surveys during calibration shows that there were on average 1.74 more whales observed on block 1 than predicted, and during the seismic survey on average 0.80 more whales observed than predicted. On block 2, the model over-predicts the number of whales during the calibration survey by an average of 1.56 whales but under-predicts it during the seismic survey by 2.71 whales. During the post-seismic period, the model is more accurate. Combined, the underpredicted densities in blocks 1 and 2 during the seismic survey $(0.80+2.71=3.51$ whales $)$ appear to account for the decrease of up to four observed whales (i.e., up to ten whales in total) on block 3 during the seismic survey.

In contrast to blocks 1 and 2, the model fits the observed data well in blocks 3 and 4 (Figs. 18, 19). 
Fig. 20 Distribution of gray whales in the Piltun survey grid during 29 July-8 September 2001
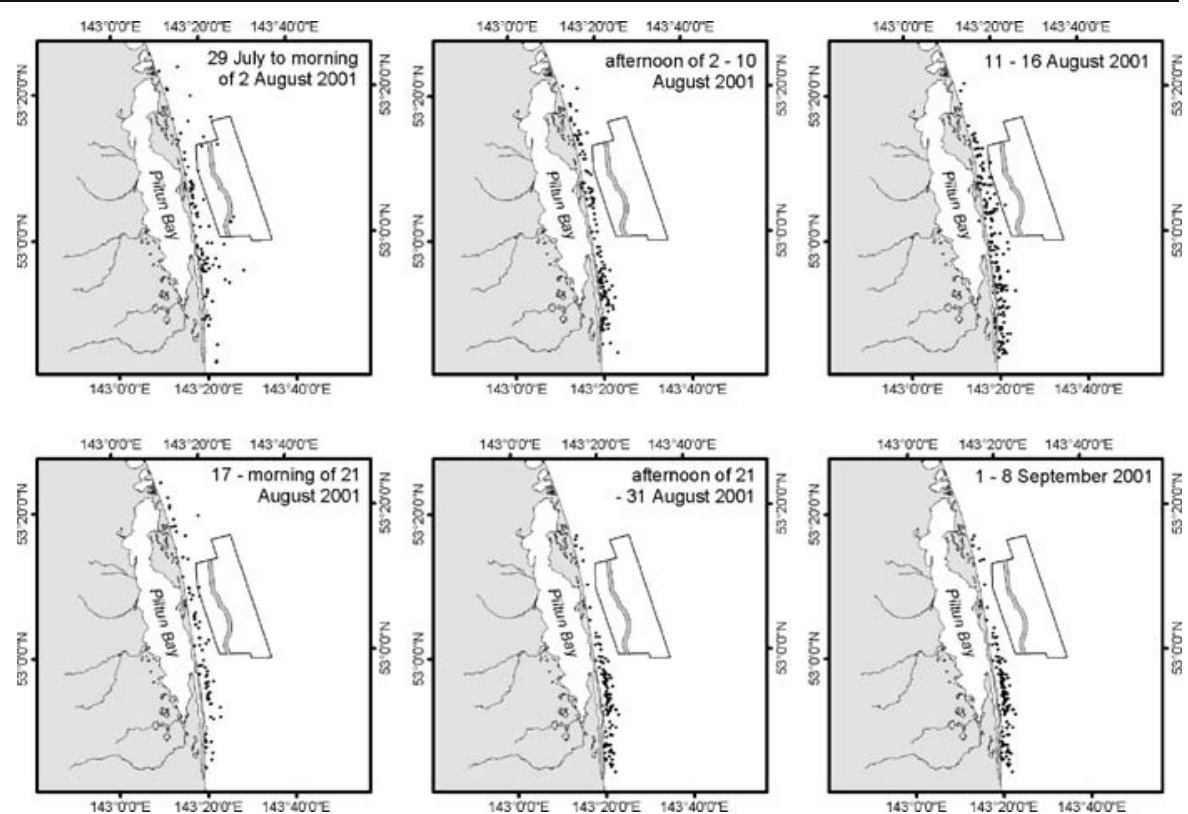

Residuals on block 3 indicate relatively good fit average residuals were 0.82 whales for the calibration survey, 0.64 whales for the seismic survey, and 0.42 for the post-seismic. Average residuals on block 4 were 0.63 whales for the calibration survey, 0.47 whales for the seismic survey, and 0.08 whales for the post-seismic.

\section{The impact of acoustic measurements on model fit}

Some of the large residuals observed on blocks 1 and 2 during the calibration survey can likely be explained by the fact that $\operatorname{seg} 3 d$ was measured over a 3-day period and, therefore, lagged behind instantaneous sound levels when the seismic survey array was ramped up or down. The variable seg $3 h$ did not explain significant portions of variance and, therefore, was excluded from the model. However, lag in seg $3 h$ does not fully explain the systematic departures from zero observed in the residuals of blocks 1 and 2 during the seismic survey. The poor fit of the model in blocks 1 and 2, particularly during the seismic survey, was likely caused by inaccuracies in the received sound energy estimates for these blocks. One possible reason why sound energy estimates in blocks 1 and 2 were less accurate than in block 3 is that the mitigation plan was designed so that most acoustical data were collected from block 3, the block that was closest to the seismic survey. In addition, sound propagation in shallow waters is complex, and the spherical sound propagation model used to construct sound energy estimates does not account for seabed topography. Bathymetry contours show a series of small ridges in the sea floor between block 3 and block 2 that could have increased attenuation of the seismic survey sounds and confounded estimation of received seismic survey sound energy in blocks 1 and 2 (C. Malme, personal communication). Bottom topography is particularly complex on block 1 . If estimates of received sound levels were too high on block 1 , it would likely cause underestimation in the number of whales. Evidence that predicted sound energy may have been overestimated for blocks 1 and 2 is provided by the more accurate fit of the data in blocks 1 and 2 during the post-seismic survey period (over-prediction of 0.75 and 0.31 whales, respectively) than during the seismic survey period.

The possible effect of the direction of sound on the distribution and abundance of gray whales was tested. It involved incorporating average unsigned source aspect (aspect or angle to the seismic survey sound source) for the preceding 3-day period (aasp3d) to the final model. The coefficient of aasp3d (aspect of the seismic survey array) was marginally not significant in this model $(p=0.0556$, approximate $F$ test). 
Significance of shifts in gray whale distribution and abundance

The mitigation program was designed to reduce the number of gray whales exposed to the target $163 \mathrm{~dB}$ re $1 \mu \mathrm{Pa}(\mathrm{rms})$ threshold at which $10 \%$ of feeding gray whales were expected to display behavioral reactions (Malme et al. 1986). It would be unreasonable to expect no behavioral reactions among gray whales at sound levels $163 \mathrm{~dB}$ re $1 \mu \mathrm{Pa}$ (rms). A statistically significant relationship was found between the seismic survey and whale density on block 3, i.e., a shift of two to four observed gray whales from block 3 (presumably southward into areas less ensonified) during periods of sustained high levels of seismic sounds. A shift was also observed by other researchers (e.g., Weller et al. 2002) who reported an increase in the number of gray whales south of the seismic block, i.e., south of block 3, during the seismic survey in 2001.
The distribution and abundance of whales within the Piltun feeding area changed over short periods in a way more complex than expected if the response was due only to seismic survey sounds near block 3 . During the calibration survey, mean latitudes of whale distribution shifted south and north several times. The observed southern shift that started around 11-16 August peaked on 21-31 August (Figs. 20 and 21). Between 1-8 September, before the seismic survey ended, whale densities began to shift north (Fig. 21) and continued until mid- to late September. Northsouth shifts in the distribution of whales in 2001 continued after the cessation of the seismic survey. In 1-10 October, most whales were distributed in two groups away from block 3 approximately $45 \mathrm{~km}$ apart. During 11-26 October and 15-19 November, the whales mostly concentrated west of block 3 and around the mouth of Piltun Bay, in a pattern similar to that observed between 2 and 10 August at the start of the calibration survey (Meier et al. 2007).
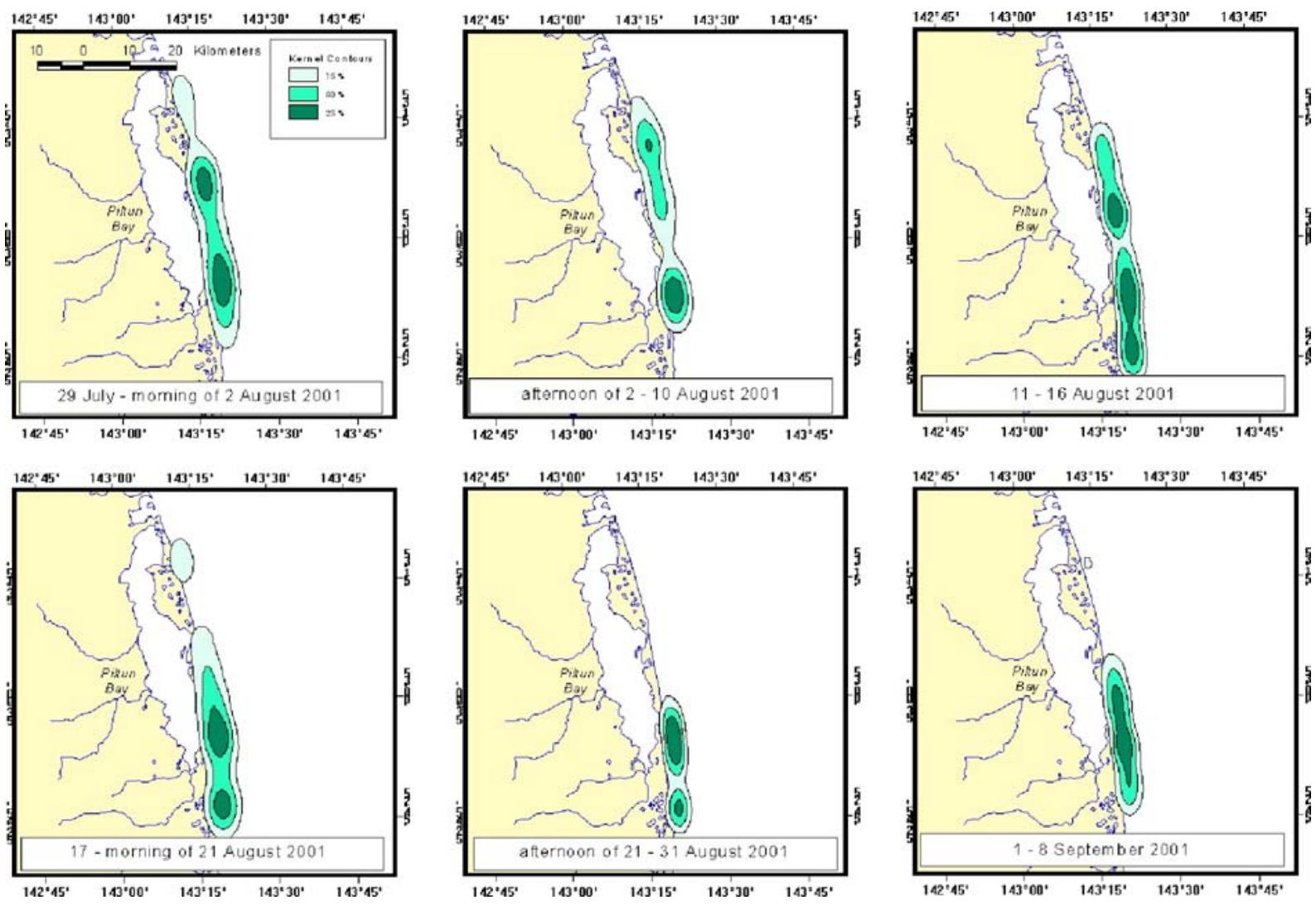

Fig. 21 Kernel densities based on the distribution of gray whales in the Piltun survey grid during 29 July-8 September 2001 
Fig. 22 Aerial survey grids flown (a) and the distribution of gray whales in 2001 based on aerial survey data (b), with gray whale observations within $1 \mathrm{~km}$ (circles) or outside $1 \mathrm{~km}$ (crosses) from the aircraft
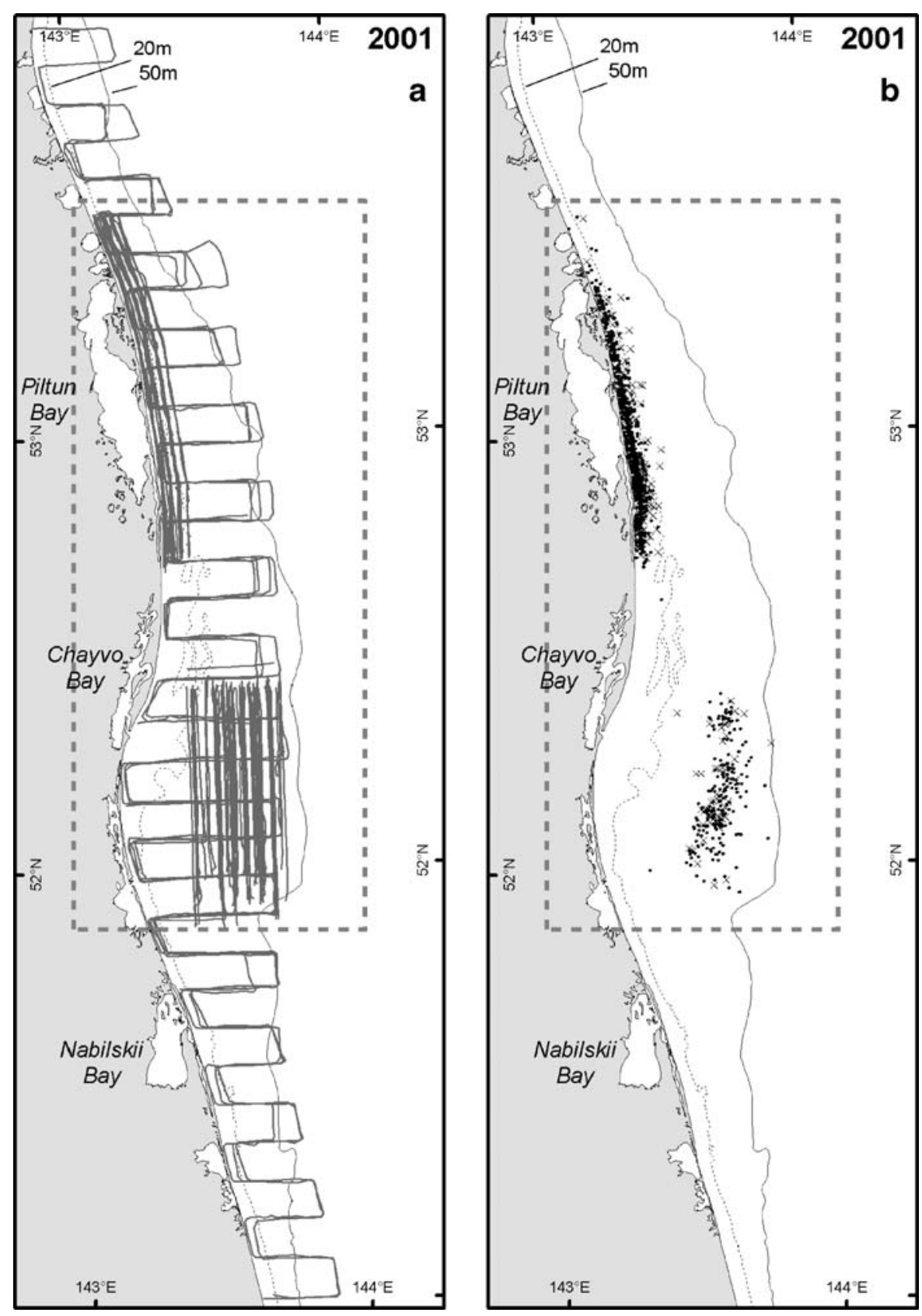

These presumably natural movements appear to have a spatial magnitude similar to the southward shift that occurred during the seismic survey (Fig. 21). Habituation of whales to seismic survey sounds may also be a possible explanation for some of the observed changes in gray whale distribution.

Local seasonal shifts have been documented in the Piltun Bay area in previous and subsequent years.
Würsig et al. (1999) reported that in 1997 the whales observed from shore from the Piltun lighthouse (Fig. 1) were concentrated north of the lighthouse in July and August, but moved south of the lighthouse in September. Photo-ID studies in the Piltun feeding area confirmed that individual whales could move up to $50 \mathrm{~km}$ along the coast in a matter of 1-2 days (Weller et al. 2000). Shifts of similar magnitude were 
Observed numbers of gray whales by survey

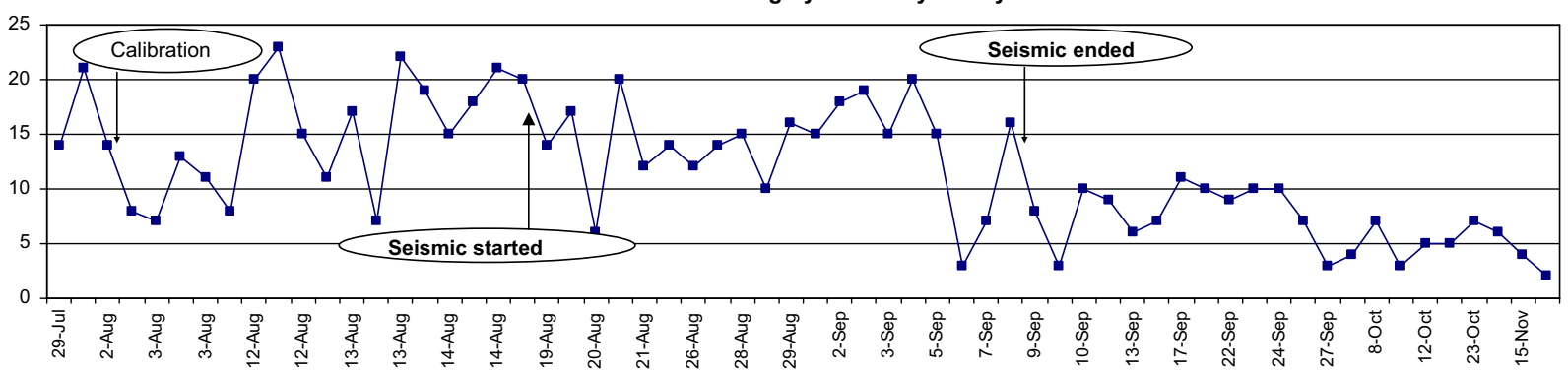

Fig. 23 Numbers of gray whales sighted during aerial surveys of the Piltun feeding area grid in 2001 within $1 \mathrm{~km}$ from the aircraft. These are raw numbers unadjusted for visibility

observed in the Offshore feeding area discovered in 2001 (Meier et al. 2007). There, in 2001 gray whale distribution shifted $\sim 15 \mathrm{~km}$ from north to south between mid-September and late October (Meier et al. 2007). Rapid shifts in whale distribution have also been documented in studies of eastern gray whales (Calambokidis et al. 2000). Individual gray whales moving $50 \mathrm{~km}$ or more in less than $24 \mathrm{~h}$ were observed, while other whales demonstrated strong site-fidelity (over days or weeks) to areas less than an acre. Studies of a small number ( 100 individuals) of resident eastern gray whales feeding in Clayoquot Sound, Canada (Bass 2000; Dunham and Duffus 2001, 2002) found that within-season and betweenseason population shifts of gray whales in this area were correlated with the distribution of food and not with human-related activities such as the presence of whale-watching vessels, as was originally presumed by both the local and scientific communities (Duffus 1996; Bass et al. 2001). Dunham and Duffus (2001, 2002) and Meier (2003) found that during the feeding season these gray whales shifted among six different feeding sites and switched between 13 prey species (benthic, epibenthic, and planktonic) within the larger region of Clayoquot Sound when (1) the biomass in one site decreased to a level where foraging was no longer energetically worthwhile, or (2) the biomass of food was greater in an alternate site. Since data on food abundance were not available for the Piltun feeding area in 2001, it was not possible to include this important factor in the quasi-likelihood regression model. Whale food studies in the Piltun feeding area in 2002, 2003 and 2004 (Fadeev 2003, $2004,2005)$ showed that feeding gray whales tend to target areas with high potential prey biomass. Throughout the 2001 feeding season, gray whales continued to occupy the Piltun feeding area. This is consistent with other studies which found that gray whales used this feeding area in every year since 1985 for which surveys were conducted (Berzin et al. 1988, 1990, 1991; Würsig et al. 1999; Sobolevsky 2000, 2001). This is also consistent with the report that western gray whales exposed to seismic survey in 1997 were not displaced away from the Piltun feeding area (Würsig et al. 1999).

There is a possibility that gray whales were feeding less during the seismic survey, and thus were less easily observable. This would represent a change in behaviour rather than distribution. Behavioural studies conducted in the same area during the 2001 seismic period found that changes in some behavioural parameters (leg speed, re-orientation rate, distance offshore, mean duration between respirations, and dive time) were statistically correlated with estimated seismic-related variables (Würsig et al. 2002; Gailey et al. 2007). It was also found that throughout the seismic survey gray whales continued to be engaged in feeding activity, as assessed by the incidence of mud plumes, and no changes in the intensity of this activity were detected (Yazvenko et al. 2007). The intensity of the feeding activity of western gray whales began decreasing after the cessation of the seismic survey in mid-September. This change in feeding activity has been shown to be a normal seasonal phenomenon observed annually (Yazvenko et al. 2002; Blokhin et al. 2003, 2004; Vladimirov et al. 2005, 2006).

Studies of western gray whales conducted in 20022005 indicate no population-level, or biologically significant effects of the 2001 seismic survey either on the number of gray whales present in subsequent years (Blokhin et al. 2003, 2004; Vladimirov et al. 2005; 
Meier et al. 2007), body condition (Weller et al. 2002, 2004; Yakovlev and Tyurneva 2003, 2004, 2005), or reproductive success (Weller et al. 2002, 2004; Yakovlev and Tyurneva 2003, 2004, 2005). Comparisons between years for all monitored behavioral parameters revealed no statistically significant differences between the results of 2001 and 2002-2003, years in which no industrial activity took place (Würsig et al. 2002, 2003; Gailey et al. 2004). Recent estimates of the size of the non-calf component of the western gray whale population indicate 122 (CI 113131) individuals in the population in $2006 \mathrm{vs}$. ca. 100 in 2001 (Weller et al. 2002). In spite of this encouraging evidence, the population remains severely endangered, and its future is highly uncertain.

\section{Conclusions}

1. The multiple regression model shows that a statistically significant redistribution of two to four observed on the surface (5-10 total) gray whales occurred within the Piltun feeding area during the 2001 Odoptu seismic survey (Fig. 22).

2. Six environmental and other unrelated to seismic survey variables (fog, white_cap, wave_height, line, block and date) and one seismic surveyrelated variable (seg3d, i.e., received sound energy accumulated over 3 days) were significantly correlated with the distribution and abundance of gray whales.

3. Throughout the seismic survey, gray whales remained in the Piltun feeding area, documented to be their main known feeding habitat since 1983 (Berzin et al. 1988, 1990, 1991; Sobolevsky 2000, 2001; Weller et al. 2000, 2001).

4. The total numbers of gray whales observed in the Piltun feeding area were approximately constant during the pre-seismic and seismic survey periods. The number of whales began to decline after the cessation of the seismic survey (Fig. 23). This gradual decline likely reflects a seasonal migration pattern of gray whales (Blokhin et al. 2003, 2004; Vladimirov et al. 2005).

5. Distribution shifts were documented in the Piltun area in 2001 during, and after the seismic survey.

6. Further studies are required to understand the distribution of food as a possible important influence on (1) the distribution and abundance of foraging gray whales in the Piltun feeding area and, (2) fluctuations in the number and distribution of foraging gray whales within and between foraging seasons. In addition, an understanding of gray whale food will likely help put into perspective the extent of both direct and indirect anthropogenic impacts on the western gray whale population.

Acknowledgements Many people helped in the collection and analysis of data and preparation of this manuscript, and many of our Russian colleagues participated in the organisation of this project. Alexander Burdin (Alaska Sealife Center) and Vyacheslav Shuntov (TINRO-Center, Vladivostok) provided valuable advice on initial design and suggested participants for the project. The support of Yuri Blinov (TINRO-Center), Vladimir Radchenko (SakhNIRO, Yuzhno-Sakhalinsk), and Anatoly Vyalov (SakhNIRO) was critical for field work.

Field support was provided by Exxon Neftegas Limited (Yuzhno-Sakhalinsk). We thank David Simerka, Brien Reep, Greg Manelick, Michael Allen, Dmitry Mayorov, Alexei Kovalev, Julian Skaretski (all from Exxon Neftegas Limited), and Julia Yazvenko (PICES, Canada) for their assistance in the field. Gennady Fedoseev and Valery Vladimirov (VNIRO, Moscow) provided valuable advice and consultation during the field program. Robin Tamasi and Lucia Ferreira (LGL) provided assistance with mapping and data analysis. W. John Richardson (LGL) provided valuable advice throughout the project. Michael Jenkerson (ExxonMobil) and Alexander Rutenko (Pacific Institute of Oceanology, Vladivostok) provided information on acoustic aspects of the study and gave critical assistance both in the field and during data analysis. Caroline Martin (ExxonMobil) gave advice and support throughout the project. The manuscript was significantly improved by the input of James Hall (ExxonMobil), Gordon Glova (LGL), Judy Muir (LGL), Lisanne Aerts (Sakhalin Energy Investment Company) and an anonymous reviewer.

This study was supported by Exxon Neftegas Limited (ENL), Yuzhno-Sakhalinsk, Russia. The preparation of this paper was jointly supported by ENL and Sakhalin Energy Investment Company, Yuzhno-Sakhalinsk, Russia.

\section{Appendix}

We adopted a quasi-likelihood regression model (McCullagh and Nelder 1989) that only assumed that the expected value and variance of $n$ were finite. Assuming that $n_{t i}$ was the number of whale groups sighted on area $t$ during flight $i$, the quasi-likelihood model is given in Eq. 4;

$\ln \left(E\left[n_{t i}\right]\right)=\ln \left(\theta_{t i}\right)+\beta_{0}+\beta_{1} X_{1 t i}+\ldots+\beta_{p} X_{p t i}$

where $\theta_{t i}$ was an offset term, $\beta_{j}$ were unknown coefficients, and $X_{j t i}$ were values of the $j$-th explanatory 
variable measured on the $t$-th area during the $i$-th survey flight. The offset term was included to convert counts into densities and is given in Eq. 5;

$\theta_{t i}=\frac{2 L_{t i}}{\widehat{f}(0) \widehat{E}_{t i}(s)}$

Under this definition of $\theta_{t i}$, the quasi-likelihood model is given in Eq. 6;

$$
\begin{aligned}
& \ln \left(E\left[n_{t i} \cdot \frac{\widehat{f}(0) \widehat{E}_{t i}(s)}{2 L_{t i}}\right]\right)=\ln \left(E\left[D_{t i}\right]\right) \\
& =\beta_{0}+\beta_{1} X_{1 t i}+\ldots+\beta_{p} X_{p t i}
\end{aligned}
$$

where $D_{t i}$ is estimated density of whales on area $t$ during flight $i$. The variance $n_{t i}$ was modeled as var $\left(n_{t i}\right)=\phi E\left[n_{t i}\right]$, where $\phi$ was an unknown over-dispersion parameter to be estimated. Quasi-likelihood approximate $F$ tests (McCullagh and Nelder 1989; Venables and Ripley 1994; McDonald et al. 2000) were employed to test for significant terms in the model. If model $M$ had $p$ parameters with residual deviance $D_{M}$, and model $m$ was a sub-model of $M$ with $q$ parameters $(p>q)$ and residual deviance $D_{m}$, the quasi-likelihood approximate $F$ test statistic was (Eq. 7);

$\frac{D_{m}-D_{M}}{\widehat{\phi}(p-q)} \sim F_{p-q, n-p}$

Over-dispersion parameter $\phi$ was estimated as the sum of squared Pearson residuals from model $M$ divided by residual degrees of freedom $n-p$. Wald $\chi^{2}$ statistics (= estimate ${ }^{2} /$ estimate's variance) were computed for individual levels of all classification variables in the model to test differences between one level and its reference.

The first analysis in the regression modelling process used stepwise variable selection to create a quasi-likelihood model containing significant environmental variables. During forward steps of the stepwise process, environmental variables in the list of variables under consideration (Table 2) were added to an existing model one-at-a-time. The significance of each added variable was determined by the approximate $F$ tests. During forward steps, the variable with the smallest $p$ value was retained in the model provided the smallest $p$ value was less than or equal to $\alpha=0.05$. Following each forward step, a backward 'look' was taken in which the significance of all variables already in the model was re-assessed. Again, significance was assessed using approximate $F$ tests. During backward looks, the variable with the greatest $p$ value was eliminated, provided its $p$ value was greater than $\alpha=0.05$. Forward steps and backward looks continued until no variables entered or exited the model. Wind direction, swell direction, and directions of the surface current, bottom current, and average current were converted to categorical variables with four categories: North $\left(315^{\circ}\right.$ to $\left.45^{\circ}\right]$, East $\left(45^{\circ}\right.$ to $135^{\circ}$ ], South $\left(135^{\circ}\right.$ to $225^{\circ}$ ], and West $\left(225^{\circ}\right.$ to $315^{\circ}$ ]. Certain variables, i.e., overcast, b_speed, c_speed, u_speed, b_dir, c_dir, u_dir, contained a large number of missing (unknown) values. To avoid complications in the model building process caused by large numbers of missing values, these variables were excluded from consideration. Although not listed in Table 2, quadratic terms for date and hour were considered for inclusion in the environmental variable model. Interactions between aircraft and visibility, white_caps, fog, and overcast were also individually considered.

Certain variables listed in Table 2 represented effects from seismic data acquisition and were only considered for inclusion after the environmental variable model was constructed. Some of these seismic surveyrelated variables relied on the definition of a ' $\mathrm{T} 1$ ' point. The T1 point for each block*line combination was the geographic center of that combination, except for cases where the geographic center was in water less than $20 \mathrm{~m}$ deep. In those cases, the $\mathrm{T} 1$ point was moved perpendicularly offshore to the closest point on the 20-m isobath (Yazvenko et al. 2002), because sonobuoys used to measure received sound levels in the study area were deployed along the $20-\mathrm{m}$ isobath, at the offshore periphery of the Piltun feeding area (Borisov et al. 2002). This shift of the $\mathrm{T} 1$ point farther offshore towards the seismic source was a conservative but necessary step to allow for a more accurate determination of estimated seismic energy reaching the block. This determination was based on case-bycase modelling of propagation from the offset $\mathrm{T} 1$ point to the geographic center of the block.

Seismic survey-related variables included estimates of total accumulated sound energy at the $\mathrm{T} 1$ point during the 3-h (seg3h) and 3-day (seg3d) period preceding an 
aerial survey flight, average unsigned aspect of the seismic exploration seismic survey airgun array to the $\mathrm{T} 1$ point during the preceding 3-h and 3-day period (aasp3h, aasp3d), and positions of the support vessels $\mathrm{m} / \mathrm{v}$ Rubin and m/v Atlas relative to the area's center for the preceding 3-h and 3-day period (rubin3h, rubin $3 d$, atlas $3 h$, atlas $3 d$ ). Values for aasp $3 h$, aasp $3 d$, rubin $3 h$, rubin $3 d$, atlas $3 h$, and atlas $3 d$ were not computable when the seismic airgun array was not present. Consequently, these variables contained a large number of missing values. Estimates of sound energy from seismic survey for specific locations and time periods were computed based on the air gun volume of the shots during that period. These estimates were computed by (1) computation of sound energy per air gun shot at $1 \mathrm{~m}$ from the source, (2) computation of sound attenuation through the water column using a simple spreading model, specifically $25^{*} \log _{10}$ (distance), (3) computation of received energy for each air gun shot by applying the spreading model to the distance between the sound source and T1 locations, and (4) summation of the resulting estimates of received energy per shot at $\mathrm{T} 1$ locations over the time period of interest.

Sound energy $1 \mathrm{~m}$ from source was estimated for 100 in. $^{3}$ (55\% of the shots), 370 in. $^{3}$ (2.5\%), 1,640 in. $^{3}(40 \%)$ and 3,090 in. $^{3}$ (2.5\% of the shots, all during calibration) air gun volumes and interpolated for remaining air gun volumes (for the approach to computing sound energy $1 \mathrm{~m}$ from source when a multiple air gun array is employed see Borisov et al. (2002) and Rutenko et al. 2007). Average energy received at $\mathrm{T} 1$ locations per shot for all shots in a given period was estimated by dividing the sum of the individual shot energies (from the previous steps) by the number of shots fired during the relevant period.

Following stepwise selection of a model containing environmental variables, seismic survey-related variables seg $3 h$, seg $3 d$, and the interactions seg $3 h^{*}$ block and $\operatorname{seg} 3 d^{*}$ block were added separately to the model containing significant environmental variables. Main effects were included in the model with interactions. Inclusion of the interaction terms allowed the relationship between sound and whale density to vary across blocks. The "best" of the four models was the one with the lowest $p$ values associated with the approximate $F$ tests. If all seismic variables had $p$ values greater than $\alpha=0.05$, i.e., their effects on the model were statistically insignificant at $\alpha=0.05$, the model containing only environmental variables would be chosen as the "best" of the four models. Significance of any seismic survey-related variable would indicate a seismic survey effect if a statistically significant portion of the variation of whale distribution could be explained by seismic survey-related variables that could not otherwise be explained by environmental conditions.

To deal with the large proportion of missing values in variables aasp $3 h$, aasp $3 d$, rubin $3 h$, rubin $3 d$, atlas $3 h$, and atlas $3 d$, primary and secondary analyses were conducted. For the primary analysis, aspect, Rubin, and Atlas variables were dropped so that aerial survey flights during periods when the seismic air gun array was not present could be retained. For the primary analysis, seismic survey sound effects were quantified by $\operatorname{seg} 3 d$ and the interaction of $\operatorname{seg} 3 d^{*}$ block and/or seg $3 h$ and the seg $3 h^{*}$ block interaction. In the secondary analysis, all flights with $\operatorname{seg} 3 d=0$ were deleted and the effects of aasp $3 h$, aasp $3 d$, rubin $3 h$, rubin $3 d$, atlas $3 h$, and atlas $3 d$ were estimated in a model containing significant environmental variables identified during the primary analysis.

To check that temporal auto-correlation in the whale density time series was not adversely affecting significance levels of terms in the final quasilikelihood model, deviance residuals (McCullagh and Nelder 1989) from the final model were assessed for temporal correlation using Moran's $I$ statistic (Moran 1950). The Moran's $I$ values vary between -1.0 and +1.0 . If the points that are close together in time have similar values, the Moran's $I$ value is high. When temporal correlation was found in the residuals, generalized mixed linear model estimation procedures were employed to allow for temporal correlation.

To aid interpretation of the final model, the predicted average number of gray whales in each block within $1 \mathrm{~km}$ of transect line 1 was computed twice for each survey. The first prediction utilized the estimated level of received seismic sound energy at each block (i.e., estimated levels of seg3h or seg3d). The second prediction assumed received sound level estimates equal 0 (i.e., no seismic survey). The second prediction estimated the average number of whales present on line 1 of a block in the absence of the seismic survey. For both predictions, weather was assumed to be ideal and all environmental variables in 
the final model were set to their most favorable levels. The difference between these two predictions was an estimate of the number of additional or missing whales associated with positive levels of received sound energy. Both predictions were plotted against time to illuminate the periods of discrepancies between the two estimates (Figs. 12, 13, 14, and 15).

The predicted average number of whales within $1 \mathrm{~km}$ of transect line 1 was calculated as follows. Assume that $n_{t i}$ was the estimated number of whale groups on block $t$ transect line 1 during survey $i$ predicted by the final model. Values for $n_{t i}$ were obtained by entering observed environmental variables and estimated sound energy values into the right-hand side of Eq. 1 for $X_{j t i}$, then multiplying by estimated values for the $\beta_{j}$, adding the observed offset $\ln \left(\theta_{t i}\right)$, and then determining the anti-logarithm (i.e., $e^{x}$ ). Values of $n_{t i}$ were not corrected for sightability, expected group size, and transect length. The total number of whales predicted to be within $1 \mathrm{~km}$ of line 1 on block $t$ during survey $i$ was estimated by correcting $n_{t i}$ for sightability and expected group size, and standardizing the area surveyed. The total number of whales was estimated as (Eq. 8);

$$
\begin{aligned}
T_{t i} & =\left[\frac{n_{t i} \widehat{f}(0) \widehat{E}_{t i}(s)}{2 L_{t i}}\right](2 L W) \\
& =\left[\frac{n_{t i}}{\exp \left(\theta_{t i}\right)}\right](2000 L)
\end{aligned}
$$

where $\widehat{f}(0)$ came from either the poor or favorable sightability model for block $t$ survey $i, W$ was the standard transect half-width $(=1000 \mathrm{~m})$, and $L$ was the average length of transects flown over block $t$ transect line 1 during each of the seismic periods (pre-seismic, calibration, seismic, post-seismic). The $95 \%$ confidence intervals for the predicted number of whales for $T_{t i}$ were calculated as $T_{t i}+/-1.96 * s e\left(T_{t i}\right)$, where the standard error of $T_{t i}$ was calculated as (Eq. 9);

$$
\operatorname{se}\left(T_{t i}\right)=\sqrt{\operatorname{var}\left(n_{t i}\right) \times\left(1 / \exp \left(\theta_{t i}\right)\right)^{2} \times(2000 L)^{2}}
$$

Here, $\operatorname{var}\left(n_{t i}\right)$ was the estimated variance of whale group counts computed from the variance-covariance matrix of the final model.

\section{References}

Anonymous (2001). Krasnaya Kniga Rossiiskoi Federatsii. Zhivotnye, [The Red Book of Russian Federation. Animals]. Ast and Astrel, Balashikha, Aginskoe, 862 pp. [available at http://www.biodat.ru/db/rb/index.htm].

Bass, J. (2000). Variations in gray whale feeding behaviour in the presence of whale-watching vessels in Clayoquot Sound, 1993-1995. Ph.D. thesis: University of Victoria, Victoria, BC. $156 \mathrm{pp}$.

Bass, J., Dunham, J., \& Duffus, D. (2001). Gray whale prey selection and prey dynamics in Clayoquot Sound, British Columbia, 1993-1997. Poster presented at the 14th Biennial Conference on the Biology of Marine Mammals, 28 November to 3 December 2001, Vancouver, British Columbia, Canada.

Berzin, A. A., Vladimirov, V. L., \& Doroshenko, N. V. (1988). Results of aerial surveys to study the distribution and abundance of cetaceans in the coastal waters of the Sea of Okhotsk in 1986-1987. In N. S. Chernysheva (Ed.), Nauchnoissledovatel'skie raboty po morskim mlekopitayushchim severnoi chasti Tikhogo okeana v 1986-1987. All-Union Research Institute for Fisheries and Oceanography (VNIRO), Moscow, USSR, pp 18-25.

Berzin, A. A., Vladimirov, V. L., \& Doroshenko, N. V. (1990). Aerial surveys to determine the distribution and number of polar whales, gray whales and beluga whales in the Sea of Okhotsk in 1985-1989. Izvestiya Tikhookeanskogo Nauchno-Issledovatel'skogo Instituta Rybnogo Khozyaistva I Okeanografii (TINRO), 112, 51-60.

Berzin, A. A., Vladimirov, V. L., \& Doroshenko, N. V. (1991). Results of aerial surveys to study the distribution and abundance of whales in the Sea of Okhotsk in 1988-1990. In L. A. Popov (Ed.), Nauchnoissledovatel'skie raboty po morskim mlekopitayushchim severnoi chasti Tikhogo okeana $v$ 1989-1990. All-Union Scientific Research Institute of Fisheries and Oceanography (VNIRO), Moscow, Russia, pp 6-17.

Blokhin, S. A. (1996). Distribution, numbers and behavior of gray whales (Eschrichtius robustus) of the American and Western populations in the areas of their distribution off the coasts of the Far East. Izvestiya Tikhookeanskogo Nauchno-Issledovatel'skogo Instituta Rybnogo Khozyaistva I Okeanografii (TINRO), 121, 36-53 (in Russian).

Blokhin, S. A., Doroshenko, N. V., \& Marchenko, I. P. (2003). The abundance, distribution, and movement patterns of gray whales (Eschrichtius robustus) in coastal waters off the northeast Sakhalin Island coast in 2002 based on the aerial survey data. Report by TINRO-Center, Vladivostok, Russia, to Exxon Neftegas Limited and Sakhalin Energy Investment Company, Yuzhno-Sakhalinsk, Russia, 29 pp. [available at http://www.sakhalinenergy.com/en/library. asp? $\mathrm{p}=$ lib_sel_western_gray_whale\&l=whale_recent_ research].

Blokhin, S. A., Maminov, M. K., \& Kosygin, G. M. (1985). On the Korean-Okhotsk population of gray whales. Report of the International Whaling Commission, 35, 375-376.

Blokhin, S. A., Vladimirov, V. L., Lagerev, S. I., \& Yazvenko, S. B. (2002). Abundance, distribution, and behavior of the 
gray whales (Eschrichtius robustus), based on aerial surveys off northeast coast of Sakhalin from July to November 2001. Report SC/02/WGW03 to Western Gray Whale Technical Committee, International Whaling Commission, Ulsan, South Korea, 41 pp.

Blokhin, S. A., Yazvenko, S. B., \& Doroshenko, N. V. (2004). Distribution, abundance, and certain behavioral traits of the Korean-Ohhotsk population of gray whales (Eschrichtius robustus) off the northeastern Sakhalin coast in the summer and fall of 2003 (based on aerial survey data from an An-28 airplane), Paper SC/56/BRG48 to the Scientific Committee, International Whaling Commission, $38 \mathrm{pp}$.

Borisov, S. V., Gritsenko, A. V., Jenkerson, M. R., Rutenko, A. N., \& Hodzevich, A. V. (2002). Evaluating and monitoring acoustic transmission from the Odoptu 3D seismic survey, 5 August-9 September, 2001. Report by V. I. Il'icev Pacific Oceanological Institute, Far East Branch of Russian Academy of Sciences, Vladivostok, Russia, and ExxonMobil Upstream Research Company, Houston, TX, for Exxon Neftegas Limited, Yuzhno-Sakhalinsk, Russia. Available from Exxon Neftegas Limited, c/o ExxonMobil Development Company, 17001 Northchase Drive \#466, Houston, TX 77060, Attn: Daniel Egging.

Buckland, S. T., Anderson, D. R., Burnham, K. P., \& Laake, J. L. (1993). Distance sampling: Estimating abundance of biological populations. London: Chapman and Hall, $446 \mathrm{pp}$.

Calambokidis, J., Darling, J. D., Deecke, V., Gearin, P., Gosho, M., Megill, W., et al. (2000). Range and movements of seasonal resident gray whales from California to southeast Alaska. Report by Cascadia Research, 2181/1 W. Fourth Avenue, Olympia, WA for the National Marine Mammal Laboratory, National Marine Fisheries Service. Seattle, WA, 29 pp.

Duffus, D. A. (1996). The recreational use of grey whales in southern Clayoquot Sound, Canada. Applied Geography, 16, 179-190.

Dunham, J. S., \& Duffus, D. A. (2001). Foraging patterns of gray whales in central Clayoquot Sound, British Columbia. Marine Ecology Progress Series, 223, 299-310.

Dunham, J. S., \& Duffus, D. A. (2002). Diet of gray whales (Eschrichtius robustus) in Clayoquot Sound, British Columbia, Canada. Marine Mammal Science, 18, 419-437.

Fadeev, V. I. (2002). Benthic research in the feeding area of the western gray whale in 2001. Report by the Institute of Marine Biology, Far East Branch of Russian Academy of Sciences, Vladivostok, Russia, for Exxon Neftegas Limited and Sakhalin Energy Investment Company, Yuzhno-Sakhalinsk, Russia, 99 pp. [available at http://www. sakhalinenergy.com/en/library.asp?p=lib_sel_western_gray_ whale\&l=whale recent research].

Fadeev, V. I. (2003). Benthos and prey studies in feeding grounds of the Okhotsk-Korean population of gray whales. Report on materials from field studies on the research vessel Nevelskoy in 2002. Report by the Institute of Marine Biology, Far East Branch of Russian Academy of Sciences, Vladivostok, Russia, for Exxon Neftegas Limited and Sakhalin Energy Investment Company, Yuzhno-Sakhalinsk, Russia, 118 pp. [available at http:// www.sakhalinenergy.com/en/library.asp?p=lib_sel_ western_gray_whale\&l=whale_recent_research].

Fadeev, V. I. (2004). Benthos and prey studies in feeding grounds of the Okhotsk-Korean population of gray whales. Report on materials from field studies on the research vessel Nevelskoy in 2003. Report by the Institute of Marine Biology, Far East Branch of Russian Academy of Sciences, Vladivostok, Russia, for Exxon Neftegas Limited and Sakhalin Energy Investment Company, Yuzhno-Sakhalinsk, Russia, 191 pp. [available at http:// www.sakhalinenergy.com/en/library.asp?p=lib_sel_ western_gray_whale\&l=whale_recent_research].

Fadeev, V. I. (2005). Benthos and food supply studies in feeding areas of the Okhotsk-Korean gray whale population. Report Based on results of field work aboard the research vessel Akademik Oparin. Report by the Institute of Marine Biology, Far East Branch of Russian Academy of Sciences, Vladivostok, Russia, for Exxon Neftegas Limited and Sakhalin Energy Investment Company, Yuzhno-Sakhalinsk, Russia, 157 pp. [available at http:// www.sakhalinenergy.com/en/library.asp?p=lib_sel_ western_gray_whale\&l=whale_recent_research].

Gailey, G., Sychenko, O., \& Würsig, B. (2004). Western gray whale behavior and movement patterns: Shore-based observations off Sakhalin Island, July-September 2003. Report for Sakhalin Energy Investment Company and Exxon Neftegas Limited, Yuzhno-Sakhalinsk, Russia, 79 pp. [available at http://www.sakhalinenergy.com/en/ library.asp?p=lib_sel_western_gray_whale\&l=whale recent research].

Gailey, G., Würsig, B., \& McDonald, T.L. (2007). Abundance, behavior, and movement patterns of western gray whales in relation to a 3-D seismic survey, Northeast Sakhalin Island, Russia. Environmental Monitoring and Assessment (this issue).

HESS (1999). High Energy Seismic Survey (HESS) review process and interim operational guidelines for marine surveys offshore southern California. Report from High Energy Seismic Survey Team for California State Lands Commission and the U.S. Minerals Management Service, Camarillo, CA, 39 pp. [available at www.mms.gov.omm/ pacific/lease/fullhessrept.pdf].

Hilton-Taylor, C. (2000). 2000 IUCN red list of threatened species. IUCN/SSC, Gland, Switzerland, and Cambridge, United Kingdom, 61 pp. (with 1 CD-ROM).

Johnson, S. R. (2002). Marine mammal mitigation and monitoring program for the 2001 Odoptu 3-D seismic survey, Sakhalin Island, Russia. Report SC/02/WGW19 to the Western Gray Whale Technical Committee, International Whaling Commission, Ulsan, South Korea, $47 \mathrm{pp}$.

Johnson, S. R., Richardson, W. J., Yazvenko, S. B., Blokhin, S. A., Gailey, G., Jenkerson, M. R., et al. (2007). A western gray whales mitigation and monitoring program for a 3-D seismic survey, Sakhalin Island, Russia. Environmental Monitoring and Assessment (this issue).

Laake, J. L., Buckland, S. T., Anderson, D. R., \& Burnham, K. P. (1993). DISTANCE user's guide. Fort Collins, CO: Colorado Cooperative Fish and Wildlife Research Unit, Colorado State University. 
LeDuc, R. G., Weller, D. W., Hyde, J., Burdin, A. M., Rosel, P. E., Brownell, R. L., Jr., et al. (2002). Genetic differences between western and eastern North Pacific gray whales (Eschrichtius robustus). Journal of Cetacean Research and Management, 4, 1-5.

Lerczak, J. A., \& Hobbs, R. C. (1998). Calculating sighting distances from angular readings during shipboard, aerial, and shore-based marine mammal surveys. Marine Mammal Science, 14, 590-599.

Littell, R. C., Milliken, G. A., Stroup, W. W., \& Wolfinger, R. D. (1996). SAS system for mixed models. Cary, NC: SAS Institute.

Malme, C. I., Würsig, B., Bird, J. E., \& Tyack, P. (1986). Behavioral responses of gray whales to industrial noise: Feeding observations and predictive modeling. Outer Continental Shelf Environmental Assessment Program, Final Report of Principal Investigators, 56, 393-600. Report 6265 (OCS Study MMS 88-0048) by Bolt Beranek \& Newman, Inc., Cambridge, MA, for National Oceanic and Atmospheric Administration, Anchorage, AK. Available as NTIS PB88-249008 from U.S. National Technical Information Service, 5285 Port Royal Road, Springfield, VA.

McCullagh, P., \& Nelder, J. A. (1989). Generalized linear models (2nd ed.). London: Chapman and Hall.

McDonald, T. L., Erickson, W. P., \& McDonald, L. L. (2000). Analysis of count data from before-after control-impact studies. Journal of Agricultural, Biological, and Environmental Statistics, 3, 262-279.

Meier, S. K. (2003). A multi-scale analysis of habitat use by gray whales (Eschrichtius robustus) in Clayoquot Sound, British Columbia, 1997-99. M.Sc. Thesis, University of Victoria, Victoria, BC, $140 \mathrm{pp}$.

Meier, S. K., Lawson, J., Yazvenko, S., Perlov, A., Maminov, M., Johnson, S. R., et al. (2002). Vessel-based marine mammal monitoring during the $20013-\mathrm{D}$ seismic survey of the Odoptu block, northeast Sakhalin Island, Okhotsk Sea, Russia. Report by LGL Limited, Sidney, BC, for Exxon Neftegas Limited, Yuzhno-Sakhalinsk, Russia, 38 pp. Available from Exxon Neftegas Limited, c/o ExxonMobil Development Company, 17001 Northchase Drive \#466, Houston, TX 77060, Attn: Daniel Egging.

Meier, S. K., Yazvenko, S. B., Blokhin, S. A., Wainwright, P. W., Maminov, M. K., \& Yakovlev, Yu. M. (2007). Distribution and abundance of western gray whales off northeast Sakhalin Island, Russia, 2001-2003. Environmental Monitoring and Assessment (this issue).

Moore, S. E., \& Clarke, J. T. (2002). Potential impact of offshore human activities on gray whales. Journal of Cetacean Research and Management, 4, 19-25.

Moran, P. A. P. (1950). Notes on continuous stochastic phenomena. Biometrika, 37, 17-23.

Rutenko, A. N., Borisov, S. V., Gritsenko, A. V., \& Jenkerson, M. R. (2007). Calibrating and monitoring the mitigation zone and estimating acoustic transmission for the 2001 3D seismic survey. Environmental Monitoring and Assessment, (this issue).

Sobolevsky, E. I. (2000). Marine mammal studies offshore northeast Sakhalin, 1999. Report by the Institute of Marine Biology, Far East Branch of Russian Academy of Sciences, Vladivostok, for Sakhalin Energy Investment Company
Limited, Yuzhno-Sakhalinsk, Russia, 149 pp. [available at http://www.sakhalinenergy.com/en/library.asp?p=lib_sel_ western_gray_whale\&l=whale_recent_research].

Sobolevsky, E. I. (2001). Marine mammal studies offshore northeast Sakhalin, 2000. Report by the Institute of Marine Biology, Far East Branch of Russian Academy of Sciences, Vladivostok, for Sakhalin Energy Investment Company Limited, Yuzhno-Sakhalinsk, Russia, 199 pp. [available at http://www.sakhalinenergy.com/en/library. asp?p=lib_sel_western_gray_whale\&l=whale_recent research].

Sokal, R. R., \& Rohlf, F. J. (1981). Biometry. The principles and practice of statistics in biological research. San Francisco, CA: Freeman, 857 pp.

Venables, W. N., \& Ripley, B. D. (1994). Modern applied statistics in S-Plus. New York: Springer-Verlag, 462 pp.

Vladimirov, V. L. (1994). Present distribution and size of the populations of whales in the Far Eastern seas. Biologiya Morya, 20, 3-13.

Vladimirov, V. A., Blokhin, S. A., Vladimirov, A. V., Vladimirov, V. L., Doroshenko, N. V., \& Maminov, M. K. (2005). Distribution and abundance of gray whales of the Okhotsk-Korean population in the Northeastern Sakhalin Waters in July-September 2004 (based on shore, aerial and vessel-based surveys). Report by the All-Russian Research Institute of Fisheries and Oceanography (VNIRO), Moscow, Russia, and the Pacific Research Center for Fisheries and Oceanography (TINRO-Center), Vladivostok, Russia, to Exxon Neftegas Limited and Sakhalin Energy Investment Company, Yuzhno-Sakhalinsk, Russia, 136 pp. [available at http://www.sakhalinenergy.com/en/library.asp?p=lib_sel_ western_gray_whale $\& \mathrm{l}=$ whale_recent_research].

Vladimirov, V. A., Blokhin, S. A., Vladimirov, A. V., Maminov, M. K., Starodymov, S. P., \& Shvetsov, E. P. (2006). Distribution and abundance of gray whales of the OkhotskKorean population off northeastern Sakhalin, JuneNovember 2005 (based on data from onshore, aerial and vessel-based surveys). Report by the All-Russian Research Institute for Fisheries and Oceanography (VNIRO), Moscow, Russia, and the Pacific Research Center for Fisheries and Oceanography (TINRO-Center), Vladivostok, Russia, to Exxon Neftegas Limited and Sakhalin Energy Investment Company, Yuzhno-Sakhalinsk, Russia, 189 pp. [available at http://www.sakhalinenergy.com/en/library.asp?p=lib_sel_ western gray whale\&l= whale recent research].

Weller, D. W., Burdin, A. M., Bradford, A. L., Ivashchenko, V., Tsidulko, G. A., Lang, A. R., et al. (2004). Western gray whales off Sakhalin Island, Russia: A joint Russia-U.S. scientific investigation July-September 2003. Report by National Marine Fisheries Service, National Oceanic and Atmospheric Administration, Southwest Fisheries Science Center, La Jolla, CA, Kamchatka Branch of Pacific Institute of Geography, Russian Academy of Sciences, Petropavlovsk, Russia, and Alaska Sealife Center, Seaward, AK, 41 pp. [available at www.ifaw.org/ifaw/dfiles/file_453.pdf].

Weller, D. W., Burdin, A. M., Bradford, A. L., Tsidulko, G. A., Ivashchenko, V., \& Brownell, R. L., Jr. (2002). Gray whales off Sakhalin Island, Russia: June-September 2001. A joint U.S.-Russian scientific investigation. Report by Texas A\&M University, Galveston, TX, Kamchatka Institute of Ecology and Nature Management, Russian 
Academy of Sciences, Petropavlovsk, Russia, and National Marine Fisheries Service, NOAA, Southwest Fisheries Science Center, La Jolla, CA, for Sakhalin Energy Investment Company Limited, Yuzhno-Sakhalinsk, Russia, 75 pp. [available at http://www.sakhalinenergy.com/en/ library.asp?p=lib_sel_western_gray_whale\&l= whale_ recent_research].

Weller, D. W., Burdin, A. M., Bradford, A. L., \& Würsig, B. (2001). Gray whales off Sakhalin Island, Russia: JuneSeptember 2000. A joint U.S.-Russian scientific investigation. Report by Texas A\&M University, Galveston, TX, and Kamchatka Institute of Ecology and Nature Management, Russian Academy of Sciences, Petropavlovsk, Russia, for Sakhalin Energy Investment Company Limited, Yuzhno-Sakhalinsk, Russia, 56 pp. [available at http:// www.sakhalinenergy.com/en/library.asp?p=lib_sel_ western_gray_whale\&l=whale_recent_research].

Weller, D. W., Würsig, B., Burdin, A. M., Reeve, S. H., \& Bradford, A. L. (2000). Gray whales off Sakhalin Island, Russia: June-October 1999. A joint U.S.-Russian scientific investigation. Report by Texas A\&M University, Galveston, TX, and Kamchatka Institute of Ecology and Nature Management, Russian Academy of Sciences, Petropavlovsk, Russia, for Sakhalin Energy Investment Company Limited, Yuzhno-Sakhalinsk, Russia, 69 pp. [available at http://www. sakhalinenergy.com/en/library.asp?p=lib_sel_ western gray_whale\&l=whale_recent_research].

Würsig, B., Gailey, G., McDonald, T.L., Nielson, R., Ortega-Ortiz, J., Wainwright, P. W., et al. (2002). Western gray whale occurrence patterns and behavior: Shore-based observations off Sakhalin Island, August-September 2001. Report by Texas A\&M University, Galveston, TX, for Exxon Neftegas Limited, Yuzhno-Sakhalinsk, Russia, 70 pp. Available from Exxon Neftegas Limited, c/o ExxonMobil Development Company, 17001 Northchase Drive \#466, Houston, TX 77060, Attention: Daniel Egging.

Würsig, B., Gailey, G., Sychenko, O., \& Petersen, H. (2003). Western gray whale occurrence patterns and behavior: Shore-based observations off Sakhalin Island, AugustSeptember 2002. Report by Texas A\&M University, Galveston, TX, for Sakhalin Energy Investment Company Limited and Exxon Neftegas Limited, Yuzhno-Sakhalinsk, Russia, 48 pp. [available at http://www.sakhalinenergy. com/en/library.asp?p=lib_sel_western_gray_whale\&l= whale recent research].

Würsig, B., Weller, D. W., Burdin, A. M., Reeve, S. H., Bradford, A. L., \& Blokhin, S. A. (2000). Gray whales summering off Sakhalin Island, Far East Russia: JulySeptember 1998. Report by Texas A\&M University, Galveston, TX, and Kamchatka Institute of Ecology and Nature Management, Russian Academy of Sciences, Petropavlovsk-Kamchatsky, Russia, for Sakhalin Energy Investment Company Limited and Exxon Neftegaz Limited, Yuzhno-Sakhalinsk, Russia, 139 pp. [available at http://www.sakhalinenergy.com/en/library.asp?p=lib_sel_ western_gray_whale\&l=whale_recent_research].
Würsig, B., Weller, D. W., Burdin, A. M., Reeve, S. H., Bradford, A. L., Blokhin, S. A., et al. (1999). Gray whales summering off Sakhalin Island, Far East Russia: JulyOctober 1997. A joint U.S.-Russian scientific investigation. Report by Texas A\&M University, Galveston, TX, and Kamchatka Institute of Ecology and Nature Management, Russian Academy of Sciences, Petropavlovsk, Russia, for Sakhalin Energy Investment Company Limited and Exxon Neftegaz Limited, Yuzhno-Sakhalinsk, Russia, 101 pp. [available at http:/www.sakhalinenergy.com/en/ library.asp?p=lib_sel_western_gray_whale\&l=whale recent_research].

Yakovlev, Yu. M., \& Tyurneva, O. Yu. (2003). Photoidentification of the Korean-Okhotsk gray whale (Eschrichtius robustus) population in 2002. Report by the Institute of Marine Biology, Far East Branch of Russian Academy of Sciences, Vladivostok, Russia, to Exxon Neftegas Limited and Sakhalin Energy Investment Company, Yuzhno-Sakhalinsk, Russia, 30 pp. [available at http://www.sakhalinenergy.com/en/library.asp?p=lib_sel_ western_gray_whale\&l=whale_recent_research].

Yakovlev, Yu. M., \& Tyurneva, O. Y̌u. (2004). Photoidentification of the Korean-Okhotsk gray whale (Eschrichtius robustus) population along the northeast coast of Sakhalin Island, Russia, 2003. Report by the Institute of Marine Biology, Far East Branch of Russian Academy of Sciences, Vladivostok, Russia, to Exxon Neftegas Limited and Sakhalin Energy Investment Company, Yuzhno-Sakhalinsk, Russia, 52 pp. [available at http://www.sakhalinenergy.com/en/library.asp?p=lib_sel_ western_gray_whale\&l=whale_recent_research].

Yakovlev, Yu. M., \& Tyurneva, O. Yu. (2005). Photographic identification of gray whales (Eschrichtius robustus) of the Korean-Okhotsk population on the northeast shelf of Sakhalin Island, Russia, 2004. Report by the Institute of Marine Biology, Far East Branch of Russian Academy of Sciences, Vladivostok, Russia, to Exxon Neftegas Limited and Sakhalin Energy Investment Company, YuzhnoSakhalinsk, Russia, 75 pp. [available at http://www. sakhalinenergy.com/en/library.asp? $p=$ lib_sel_western gray_whale\&l=whale_recent_research].

Yazvenko, S. B., McDonald, T. L., Blokhin, S. A., Johnson, S. R., Melton, H. R., Newcomer, M. W., et al. (2007). Feeding of western gray whales during a seismic survey near Sakhalin Island, Russia. Environmental Monitoring and Assessment (this isuue).

Yazvenko, S. B., McDonald, T. L., Meier, S. K., Blokhin, S. A., Johnson, S. R., Vladimirov, V., et al. (2002). Aerial marine mammal monitoring during the 2001 3-D seismic survey of the Odoptu block, northeast Sakhalin Island, Okhotsk Sea, Russia. Report by LGL Limited, Sidney, BC, for Exxon Neftegas Limited, YuzhnoSakhalinsk, Russia, 153 pp. Available from Exxon Neftegas Limited, c/o ExxonMobil Development Company, 17001 Northchase Drive \#466, Houston, TX, 77060, Attn: Daniel Egging. 